This item was submitted to Loughborough's Research Repository by the author.

Items in Figshare are protected by copyright, with all rights reserved, unless otherwise indicated.

\title{
The dynamics of droplet impact on a heated porous surface
}

\section{PLEASE CITE THE PUBLISHED VERSION}

https://doi.org/10.1016/j.ces.2018.06.030

\section{PUBLISHER}

(c) Elsevier

\section{VERSION}

AM (Accepted Manuscript)

\section{PUBLISHER STATEMENT}

This work is made available according to the conditions of the Creative Commons Attribution-NonCommercialNoDerivatives 4.0 International (CC BY-NC-ND 4.0) licence. Full details of this licence are available at: https://creativecommons.org/licenses/by-nc-nd/4.0/

\section{LICENCE}

CC BY-NC-ND 4.0

\section{REPOSITORY RECORD}

Zhao, Peng, Graham Hargrave, Hendrik Versteeg, Colin Garner, Benjamin A. Reid, Edward Long, and Huayong Zhao. 2019. "The Dynamics of Droplet Impact on a Heated Porous Surface". figshare. https://hdl.handle.net/2134/33604. 


\section{Accepted Manuscript}

The dynamics of droplet impact on a heated porous surface

P. Zhao, G.K. Hargrave, H.K. Versteeg, C.P. Garner, B.A. Reid, E.J. Long, H. Zhao

PII:

S0009-2509(18)30399-3

DOI: https://doi.org/10.1016/j.ces.2018.06.030

Reference: CES 14304

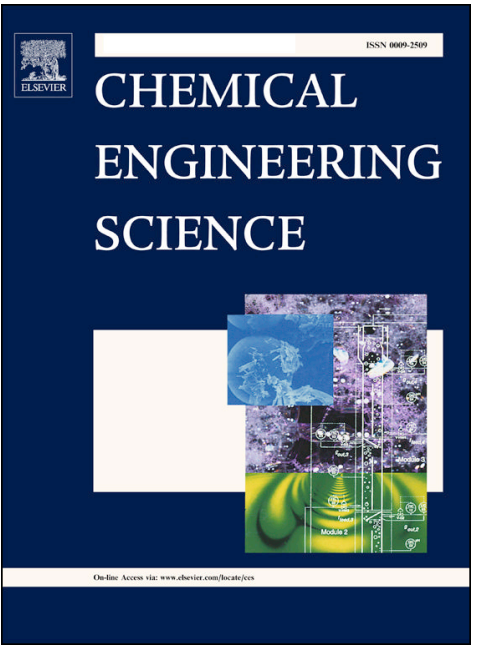

To appear in: $\quad$ Chemical Engineering Science

Received Date: $\quad 12$ January 2018

Revised Date: $\quad 8$ June 2018

Accepted Date: $\quad 12$ June 2018

Please cite this article as: P. Zhao, G.K. Hargrave, H.K. Versteeg, C.P. Garner, B.A. Reid, E.J. Long, H. Zhao, The dynamics of droplet impact on a heated porous surface, Chemical Engineering Science (2018), doi: https://doi.org/ 10.1016/j.ces.2018.06.030

This is a PDF file of an unedited manuscript that has been accepted for publication. As a service to our customers we are providing this early version of the manuscript. The manuscript will undergo copyediting, typesetting, and review of the resulting proof before it is published in its final form. Please note that during the production process errors may be discovered which could affect the content, and all legal disclaimers that apply to the journal pertain. 


\title{
The dynamics of droplet impact on a heated porous surface
}

\author{
P. Zhao*, G.K. Hargrave, H.K. Versteeg, C.P. Garner, B.A. Reid, E.J. Long, H. Zhao \\ Wolfson School of Mechanical and Manufacturing Engineering, Loughborough University, Loughborough, LE11 3TU, United Kingdom \\ * Corresponding author. E-mail address: p.zhao@lboro.ac.uk (P. Zhao)
}

\begin{abstract}
In this paper, droplet impact on a porous surface is experimentally investigated over a wide range of Weber numbers and surface temperatures. Regime transition criteria have been deduced to determine droplet post-impingement behaviour as a function of the Weber number and surface temperature for which a droplet impacting on a porous surface. Based on the energy balance, an analytical model with improved boundary layer description is proposed to predict maximum spreading of droplet following impact on porous surfaces when the effect of heat transfer is negligible. The results of the model indicate that the spreading process after droplet impact on porous surfaces is governed by the viscous dissipation and matric potential. The maximum-spread model predictions agreed well with experimental measurements reported in this paper and the literature over a large range of Weber numbers and different porous surfaces.
\end{abstract}

\section{Highlights:}

-The dynamics of droplet impact on a heated porous surface is studied experimentally.

-A new impact regime map together with regime transition criteria is proposed to determine droplet post-impingement behaviour.

-Significant differences are found between droplet impact on impermeable surfaces and porous surfaces.

-An analytical model with improved boundary layer description is developed to predict maximum spreading.

-The maximum-spread model predictions agree well with experiments.

\section{Keywords:}

Droplet impact

Porous surface

Impact regime

Maximum spreading 


\section{Nomenclature}

\begin{tabular}{|llll|}
\hline$A$ & area, $\mathrm{m}^{2}$ & \multicolumn{2}{l|}{ Greek symbols } \\
$D$ & diameter, $\mathrm{m}$ & $\mu$ & dynamic liquid viscosity, Pa·s \\
$E$ & energy, $\mathrm{J}$ & $\rho$ & liquid density, $\mathrm{kg} / \mathrm{m}^{3}$ \\
$g$ & gravitational acceleration, $\mathrm{m} / \mathrm{s}^{2}$ & $\sigma$ & surface tension, $\mathrm{N} / \mathrm{m}$ \\
$h$ & height, $\mathrm{m}$ & $\theta$ & contact angle, $^{\mathrm{o}}$ \\
$l$ & length, $\mathrm{m}$ & $\eta$ & porosity \\
$O h$ & Ohnesorge number & $\phi$ & viscous dissipation function, $\mathrm{N} /\left(\mathrm{m}^{2} \cdot \mathrm{s}\right)$ \\
$P$ & pressure, Pa & $\delta$ & boundary layer thickness, $\mathrm{m}$ \\
$Q$ & heat, $\mathrm{J}$ & $\beta$ & spreading ratio \\
$r$ & radius, $\mathrm{m}$ & $l$ & contact line dimensionless length \\
$R e$ & Reynolds number & & \\
$T$ & temperature, ${ }^{\circ} \mathrm{C}$ & Subscripts & \\
$t$ & time, $\mathrm{s}$ & 0 & initial condition \\
$U$ & velocity, $\mathrm{m} / \mathrm{s}$ & $l$ & at the maximum spreading \\
$V$ & volume, $\mathrm{m}^{3}$ & $d$ & droplet \\
$W e$ & Weber number & $i$ & direction \\
$x$ & x-direction & $j$ & direction \\
& & $l$ & liquid \\
& & $S$ & surface \\
\hline
\end{tabular}

\section{Introduction}

Developing an understanding of the behaviour of liquid droplets impacting on porous surfaces and the subsequent spreading process is significant in many industrial applications. In transportation, recent developments in selective catalytic reduction (SCR) for Diesel engines (Lockyer et al., 2015) requires control of the impingement process of urea droplets on porous catalyst surfaces to optimize the decomposition processes that generate ammonia which is used to reduce NOx emissions. In the manufacturing industry, binder jetting technology is used to construct parts such as skeletal replacements and porous biological scaffolds for reconstructive surgery (Wang et al., 2015). In the pharmaceutical industry, tablet coatings, used for protection or to control drug release, rely on accurate control of the wetting of porous surfaces (Bolleddula et al., 2010). Other application areas include ink jet printing, needle-less injection, aerosol filtering systems and raindrop penetration into building materials (Abuku et al., 2009). Accurate control of droplet impact on these porous surfaces is essential to create the desired physical and chemical processes. Therefore, knowledge of droplet impact behaviour and post-impingement characteristics is essential to optimise their performance.

Droplet impact regimes: In the study of droplet impact, two dimensionless numbers, defined based on the droplet properties, are widely used to characterise the impact dynamics:

Weber number, $W e=\frac{\rho_{l} U_{0}^{2} D_{0}}{\sigma}$

Reynolds number, $\operatorname{Re}=\frac{\rho_{l} U_{0} D_{0}}{\mu_{l}}$

The Weber number is used to assess the relative importance of the droplet inertia compared with the surface tension and Reynolds number defines the relative importance of the droplet inertia and the viscous force. Incorporating these two 
dimensionless numbers, different types of droplet impact behaviour and post-impingement characteristics on impermeable surfaces have been reported over the last thirty years (Bai and Gosman, 1995; Mundo et al., 1998; Naber and Reitz, 1988; O'Rourke and Amsden, 2000; Senda et al., 1997). In the study of droplet impact on porous surfaces, researchers (Jeong et al., 2005) have often used the impact regimes model developed for droplet/impermeable surface interactions (Bai and Gosman, 1995). Figure 1.a. and 1.b. show two models of droplet impact regimes and transition conditions for impermeable surfaces (Bai and Gosman, 1995; Staat et al., 2015). For example, the Bai-Gosman model defines the transitions between the various regimes of impact behaviour (Figure 1.a.), such as spread, splash and break-up, and defines criteria for regime transition for droplet impact over a wide range of Weber numbers and surface temperatures. $T_{p a}$ is the pure adhesion temperature (the liquid boiling temperature); $T_{N}$ is the Nakayama temperature, when a droplet reaches its maximum evaporation rate; $T_{\text {Leid }}$ is the Leidenfrost point (LFP), the minimum evaporation temperature; and $W e_{C}$ is the critical Weber number (splash threshold). Different impact regime maps may use different definitions of the impact regimes and boundaries between different impact regimes (Bai and Gosman, 1995; Bernardin et al., 1997; Bertola, 2015; Castanet et al., 2009; Lee and Ryu, 2006; Staat et al., 2015; Tran et al., 2012), but there have many features in common with the different impact regime maps, such as typical impact behaviours. By comparing different impact regime maps (Bai and Gosman, 1995; Bertola, 2015; Staat et al., 2015; Tran et al., 2012), the common features of different impact regime maps based on Weber numbers and surface temperatures are summarised. Firstly, the droplet sticks to/spreads on the surface at lower We and lower $T_{s}$ (surface temperature). Secondly, the droplet rebounds over the surface at lower We and higher $T_{s}$ (Leidenfrost point normally). Finally, the regime is splash/break up at higher We and regardless the $T_{s}$. Besides the droplet properties and surface temperature, impact regime maps are also dependent on surface morphology that causes different impact behaviours and boundaries between impact regimes, such as polished silicon plates (Tran et al., 2012), polished aluminium surface (Bertola, 2015), sapphire plate (Staat et al., 2015). Identifying the transitions between the modes of interaction allows the development of models defining post-impingement characteristics and droplet contact surface area to determine thermal and mass transfer. For droplet impact on impermeable surfaces, these models have been proven to provide an accurate description of surface interaction (Bai and Gosman, 1995; Bertola, 2015; Jia et al., 2008; Staat et al., 2015; Tran et al., 2012). However, current droplet impingement models for impermeable surfaces cannot predict droplet impact on porous surfaces accurately. 


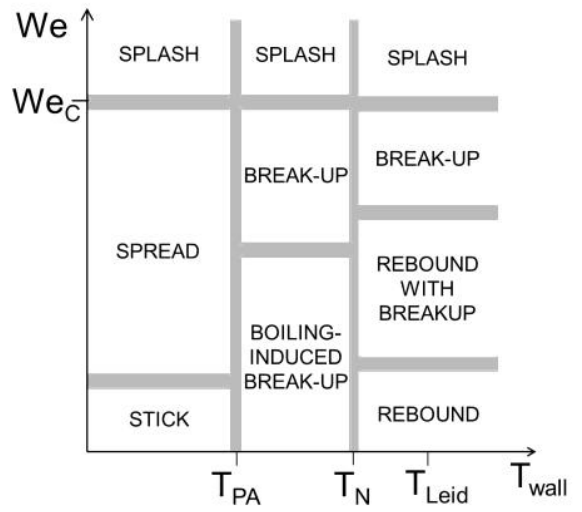

(a)

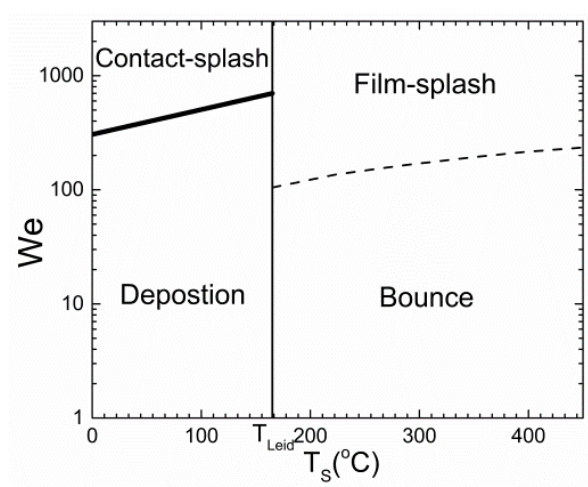

(b)

Fig. 1. Droplet impact regimes and transition conditions for impermeable surfaces (a) (Bai and Gosman, 1995); (b) (Staat et al., 2015)

There have been many studies reporting experimental research into droplet impact on porous surfaces at ambient temperature (Joung and Buie, 2014; J B Lee et al., 2016a, 2016b) and high temperature (Avedisian and Koplik, 1987; Chandra and Avedisian, 1992; Kim and Lee, 2014; Yu et al., 2008). The studies of droplet impact on heated porous surfaces provided visualisation of droplet behaviour for a range of liquids (water, methanol and heptane), Weber numbers (9.6 - 200.0), surface porosities $(0.1-0.4)$, and surface temperatures $\left(22^{\circ} \mathrm{C}-371.9^{\circ} \mathrm{C}\right)$. Overview of experimental results is shown in Figure 2 . Based on the experimental results, droplet behaviours have been classified into different regimes based on the We and surface temperature. High-resolution imaging provides useful insights into the behaviour of impacting droplets and characterises the impact regimes. However, the results from these studies are often contradictory. Various impaction regimes are defined, but the regime transition criteria vary considerably between studies and even the regime descriptors are not consistent or clearly defined. 


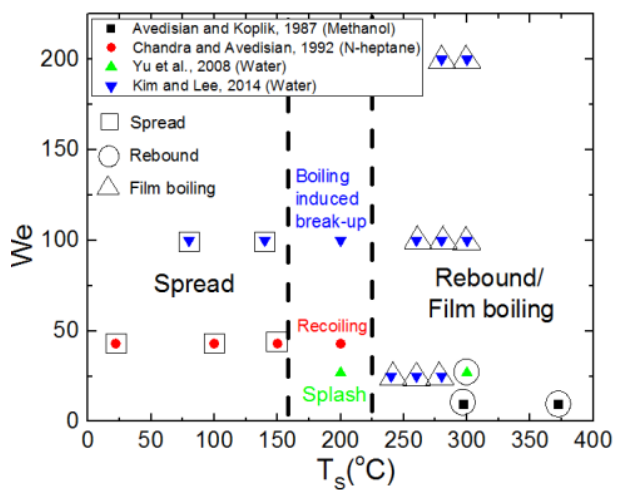

Fig. 2. Overview of experimental work of droplet impact on heated porous surfaces studies (Avedisian and Koplik, 1987; Chandra and Avedisian, 1992; Kim and Lee, 2014; Yu et al., 2008) (Properties of porous material: 1987 alumina, porosity $0.1-0.25, D_{\text {grain }}=50 \& 5-10 \mu$ m; 1992 alumina, porosity $0.25, D_{\text {grain }}=5-10 \mu \mathrm{m} ; 2008 \mathrm{R}_{-} \mathrm{Al}_{2} \mathrm{O}_{3}$, porosity $0.34, D_{\text {grain }}=0.076 \mu \mathrm{m} ; 2014$ glass-beads, porosity $0.38, D_{\text {grain }}=63.9-$ $269 \mu \mathrm{m})$

An important feature of the droplet-surface interaction is whether Leidenfrost phenomenon, which plays a crucial role in the Bai-Gosman map for solid surfaces, occurs on surfaces with high porosity. The traditional Leidenfrost phenomenon is explained by the compressibility or the stability of the vapour layer underneath the droplet (Gottfried and Bell, 1966), but the effects of both compressibility and stability will be significantly reduced in high porosity substrate since the vapour can escape through the voids. Studies have shown that LFP increases with decreasing porous grain size (63.9 - $269 \mu \mathrm{m}$, glass beads) (Kim and Lee, 2014) and with increasing surface porosity (0.1 - 0.25, alumina) (Avedisian and Koplik, 1987). It has also been clearly shown that the LFP changes with liquid (acetone, benzene, FC-72, and water), surface properties (stainless steel, Graphite, Brass, Copper, Pyrex etc.) and micro/nanostructured surfaces (Arnaldo Del Cerro et al., 2012; Bernardin and Mudawar, 1999; Kim et al., 2011; Kruse et al., 2013; Kwon et al., 2013; Nair et al., 2014; Talari et al., 2018; Weickgenannt et al., 2011).

As shown in Figure 2, an aspect of the droplet-surface interaction that is missing from the current high-temperature porous surface data is the splash phenomenon. The Bai-Gosman model defines a critical Weber number, $W e_{C}$, above which the interaction is defined by the 'splash' phenomenon at all surface temperatures.

$W e_{C}=A \cdot L a^{-0.18}$

where $L a=\rho_{l} \sigma D_{0} / \mu_{l}^{2}$. Coefficient $A$ is reported to increase with decreasing surface roughness (Bai and Gosman, 1995). It appears that for the presented data for impact on high temperatures porous surfaces (Avedisian and Koplik, 1987; Chandra and Avedisian, 1992; Kim and Lee, 2014; Yu et al., 2008) that the Weber numbers (9.6 - 200.0) are not high enough to exceed $W e_{C}$. In order to provide data for the development and validation of models for the design of optimised SCR systems, the current study will extend the Weber number range for droplet-high temperture porous surface interactions to examine the splash regime. Data is also provided for the high temperature surface interactions seen in exhaust after-treatment systems. 
Maximum spreading diameter $\left(\boldsymbol{D}_{\text {max }}\right)$ : The maximum spreading diameter has been reported to be one of the most important parameters in many applications. In SCR systems, the maximum spreading diameter affects the heat transfer from the wall to the liquid which is crucial for the evaporation and thermolysis of urea-water-solution and the deposit formation (Lockyer et al., 2015). The binder droplet maximum spreading performance on the surface of hydroxyapatite microspheres can affect the quality of printed bone scaffolds (Wang et al., 2015). In addition, raindrop penetration into building materials is reported to be correlated to the maximum spreading diameter of the raindrops (Abuku et al., 2009).

Empirical correlations: Scaling analysis has been applied to study the $D_{\max }$ based on experimental data of droplet impact on impermeable surfaces. One of the frequently used empirical correlations in commercial CFD codes FLUENT, STAR-CCM+, VECTIS was reported by Akao et al. (Akao et al., 1980):

$D_{\max }=D_{0} 0.61 W e^{0.38}$

This correlation was developed for dry and impermeable surfaces with surface temperature lower than the LFP. Araki and Moriyama (Araki and Moriyama, 1980) validated Equation 4 with the experimental data of water droplet impact on a hot metal surface heated up to $800^{\circ} \mathrm{C}$. It was noted by Laan et al. (Laan et al., 2014) that the scaling with $W e^{0.38}$ cannot predict $D_{\max }$ accurately for droplets of water-glycerol mixtures or blood impacting on stainless steel surfaces. Different correlations for $D_{\max }$ have been reported for different combinations of fluids and surface, such as $W e^{0.25}$ (water, copper) (Ng et al., 2015), $W e^{0.3}$ (water, micro structured silicon surface) (Tran et al., 2013), We $e^{0.38}$ (Water \& FC-72, polished silicon wafer) (Tran et al., 2012), $W e^{0.4}$ (water, polished aluminum \& silicon wafer) (Antonini et al., 2013). Lee et al. (2016) collaped their data into a curve by using the Padé approximation $\left(\beta_{\max }^{2}-\beta_{U_{i}=0}^{2}\right)^{1 / 2} R e^{-1 / 5}=W e^{1 / 2} /\left(A+W e^{1 / 2}\right)$ for porous and non-porous surfaces $\left(\beta_{U_{i}=0}\right.$ : the maximum spreading ratio at zero impact velocity, A: a fitting constant) (J B Lee et al., 2016a). Different scaling laws of the maximum spreading ratio will be examined in this study. The objective of the scaling analysis in the present study is to evaluate whether the $D_{\max }$ of porous surfaces can be depicted by the physics developed for impermeable surfaces.

Analytical studies: In a study of droplet impact on a cold solid surface, Madejski (Madejski, 1976) developed the first analytical model of droplet impact dynamics using the variational principle. Over the past 30 years, development and improvement of analytical models have focused on droplet-impermeable surface interactions (Attané et al., 2007; Bang et al., 2011; Bechtel et al., 1981; Chandra and Avedisian, 1991; Kendall and Rohsenow, 1978; Kim and Chun, 2001; Mao et al., 1997; Pasandideh-Fard et al., 1996; Ryu and Lee, 2009; Tang et al., 2017; Ukiwe and Kwok, 2005; Yonemoto and Kunugi, 2017). The analytical study is capable of predicting $D_{\max }$ based on the conservation of energy or momentum.

The energy balance model is formulated in terms of the conservation of the sum of kinetic energy, surface energy and viscous dissipation. Different versions address the estimation of surface energy and viscous dissipation. The surface energy term requires an accurate and simple description of the surface geometry (Mao et al., 1997) and the contact angle (Jae Bong Lee et 
al., 2016; Ukiwe and Kwok, 2005). Different models of the viscous dissipation involve various accounts of time to maximum spread (Pasandideh-Fard et al., 1996) and boundary layer thickness (Bechtel et al., 1981; Chandra and Avedisian, 1991; Pasandideh-Fard et al., 1996).

A momentum/force balance model has also been developed to predict $D_{\max }$ (Clanet et al., 2004). The model predicts $D_{\max }$ using the capillary length $(a=\sqrt{\sigma / \rho g})$, the deceleration $\left(U_{0}^{2} / D_{0}\right)$ of the droplet and volume conservation. A non-dimensional number $\left(P=W e / R e^{4 / 5}\right)$ was also proposed to characterise the viscous regime $\left(P>1, D_{\max } \propto D_{0} R e^{1 / 5}\right)$ and the capillary regime $\left(P<1, D_{\max } \propto D_{0} W e^{1 / 4}\right)$. The predictions agree well with experiments. Both the energy balance model and momentum model are able to predict $D_{\max }$ in the spread regime (low We). Recent developments based on energy balance or/and momentum/force balance have shown some improvement in predictions of $D_{\max }$ of droplet impact on impermeable surfaces by considering the geometrical head loss, the momentum balance of the rim or the adhesion energy (Roisman et al., 2002; Wildeman et al., 2016; Yonemoto and Kunugi, 2017). Comprehensive reviews on $D_{\max }$ of droplet impact on impermeable surfaces can be found in the literature (Josserand and Thoroddsen, 2016; Marengo et al., 2011; Yarin, 2005).

Porous surfaces: Limited analysis has been carried out on the maximum spread of droplets impacting on porous surfaces. Dynamics of spreading on highly wetting porous surfaces were considered by Joung and Buie (Joung and Buie, 2014), who proposed an energy balance to predict droplet spreading rate. However, the transient analytical approach is complex and timeconsuming, which limits its broader application. Lee et al. (J B Lee et al., 2016a) added the initial surface energy to the scaling analysis for both impermeable surface and porous surfaces. They assume that droplet impact on the porous surface is dominated by kinetic energy, initial surface energy and surface energy at the maximum spreading for low porosity surfaces $(5.1 \%-26.9 \%)$. However, Joung and Buie have shown that the matric potential represents a significant proportion of the total energy at the maximum spreading and viscous dissipation during the process of droplet impact and therefore cannot be ignored (Joung and Buie, 2014).

Purpose and aims of this study: In this study, experimental data are presented for impact behaviour of water droplets on a porous ceramic substrate over a wide range of Weber numbers and surface temperatures. The study is part of a project to develop high-efficiency SCR systems in diesel engine applications and aims to generate and discuss a detailed impact regime map over a wide range of Weber numbers and surface temperatures on a widely used cordierite porous surface. Cordierite $\left(2 \mathrm{MgO} \cdot 2 \mathrm{Al}_{2} \mathrm{O}_{3} \cdot 5 \mathrm{SiO}_{2}\right)$ has good mechanical strength, low thermal expansion coefficient, good surface properties, and is costeffective (Valášková and Martynková, 2009). In addition, Cordierite ceramics can be used up to approximately $1200^{\circ} \mathrm{C}$ (Rohan et al., 2004) so they are widely used in SCR systems and other high temperature chemical engineering systems. The data generated from this study is vital to understand and predict the physical and chemical process in order to develop a highefficiency SCR systems (Lockyer et al., 2015) and in other applications using high-temperature porous substrates. 
The quantitative data on maximum spreading ratio during the droplet impact process produced in this study is compared with existing scaling laws to test their validity. Moreover, an analytical model based on the energy balance with improved boundary layer description is proposed to predict maximum spreading of droplet following impact on porous surfaces when the effect of heat transfer is negligible. The predicted maximum spreading ratios from the proposed model are then compared to the experimental data generated in this study and the data reported in the literature on other types of porous surfaces to test the validity of the model.

\section{Impact regimes and transition criteria of droplet-porous surface interaction}

\subsection{Experimental method}

In order to obtain impact regimes for droplet-porous surface interactions, experiments of water droplet impact on a cordierite porous surface. To make it possible to compare the differences between droplet impact on porous and impermeable surfaces in the same test setup, a set of droplet impact experiments was carried out using a smooth stainless steel surface at ambient conditions.

Figure 3 shows a schematic of the experimental set-up. Single droplets of water were generated by means of a syringe pump (TSI Model 3450 aerosol generator) and a needle nozzle (BD Medical). Videos of the droplet impact process were obtained by a high-speed camera (Photron APX-RS) operating at 10000 frames/s and $512 \times 208$ pixels resolution. The imaging lens used was a Nikon $200 \mathrm{~mm}$ Micro Nikkor lens and the light source was a $100 \mathrm{~W}$ LED fitted with a glass diffuser. The cordierite porous surface was heated by an electric ceramic hotplate over the temperature range $50^{\circ} \mathrm{C}-450^{\circ} \mathrm{C}$. The surface temperatures were measured using a K-type surface thermocouple (Omega SA1XL) connected to a data logger (Pico TC80 thermocouple data logger). An infrared camera (FLIR E60) was used to monitor the surface temperature over an extended area. The surface temperature measured by the surface thermocouple was used to calibrate the temperature measurement by the infrared camera.

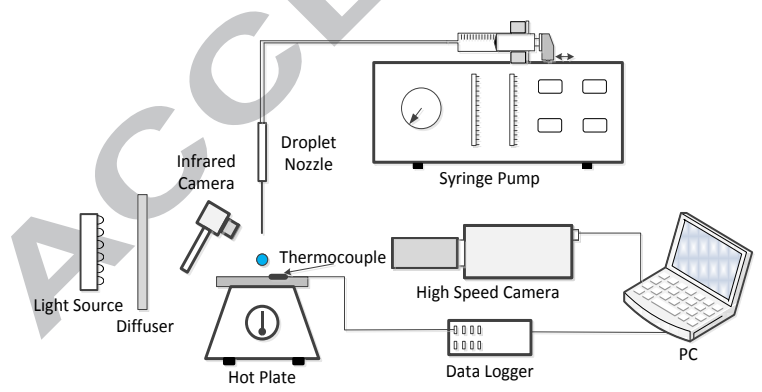

Fig. 3. Schematic diagram of experimental setup 
The mean diameter of the droplets produced by the system was $2.2 \mathrm{~mm}$. The droplet impact velocity was controlled by changing the vertical distance between the nozzle tip and the porous surface. The displacement of the droplet between successive frames of the recorded video just before impact was used to calculate the droplet impact velocity. The droplet impact velocity ranged from $0.4 \mathrm{~m} / \mathrm{s}$ to $4.1 \mathrm{~m} / \mathrm{s}$, giving a Weber number in the range 5 to 500 .

Figure 4 shows the images of the cordierite porous surface captured by a scanning electron microscopy (Hitachi TM3030) allowing analysis of the surface to determine the structure, grain size and pore size.

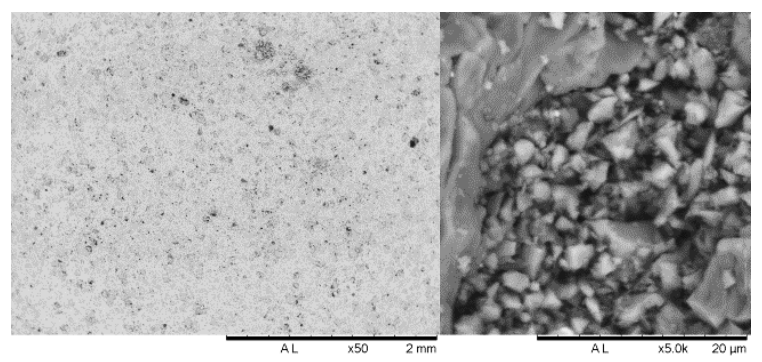

Fig. 4. Scanning electron microscope (SEM) images of cordierite porous surface by carbon coating

Table 1 shows the properties of the liquid droplets and the cordierite porous surface. The thermal conductivity of AISI 304 stainless steel is $14.92-24.33 \mathrm{~W} /(\mathrm{m} \cdot \mathrm{K})(T=333.7 K-975.3 \mathrm{~K})$ (Graves et al., 1991). The thermal conductivity of the cordierite $(0.921 \mathrm{~W} /(\mathrm{m} \cdot \mathrm{K})$ (Zygourakis, 1989)) is much smaller than that of the stainless steel. The cordierite is a poor thermal conductor (lower heat transfer rate) and cools down during the droplet impact process significantly compared with stainless steel surface (Hahn and Özışı, 2012). Consequently, the effect of time-averaged surface temperature on droplet impact behaviour on the cordierite substrate can be different from the behaviour on impermeable surfaces of high thermal conductivity, especially at high temperature. Therefore, different regimes are expected for droplet impact on heated cordierite porous surface compared with impermeable surfaces. 
Table 1. Properties of liquid droplets and porous surface

\begin{tabular}{ll}
\hline Parameters & Properties \\
\hline Mean droplet diameter & $2.2 \pm 0.05 \mathrm{~mm}$ \\
Liquid & Water \\
Density & $998 \mathrm{~kg} / \mathrm{m}^{3}$ \\
Viscosity & $0.001 \mathrm{~Pa} \cdot \mathrm{s}$ \\
Surface tension & $0.0728 \mathrm{~N} / \mathrm{m}$ \\
Velocity & $0.4 \pm 0.005-4.1 \pm 0.01 \mathrm{~m} / \mathrm{s}$ \\
Weber number & $5-500$ \\
Surface temperature & $50 \pm 1-450 \pm 1^{\circ} \mathrm{C}$ \\
Surface material & Cordierite \\
Effective grain size & $10 \mu \mathrm{m}$ \\
Effective pore size & $6 \mu \mathrm{m}$ \\
Solid bulk density* & $1536.9 \mathrm{~kg} / \mathrm{m}^{3}$ \\
Thermal conductivity* & $0.921 \mathrm{~W} /(\mathrm{m} \cdot \mathrm{K})$ \\
Specific heat capacity*** & $0.475 \mathrm{~J} /(\mathrm{g} \cdot \mathrm{K})\left(0-100^{\circ} \mathrm{C}\right)$ \\
\hline \multicolumn{2}{c}{$*($ Zygourakis, 1989$)$} \\
*** $($ Day, 1996$)$
\end{tabular}

A typical sequence of images of the spreading liquid film is presented in Figure 5. From these images, the spreading diameter was measured as the horizontal edge-to-edge distance of the fluid film. The maximum spreading ratio is defined as the maximum diameter during impact divided by droplet diameter just before impact $\left(\beta_{\max }=D_{\max } / D_{0}\right)$.

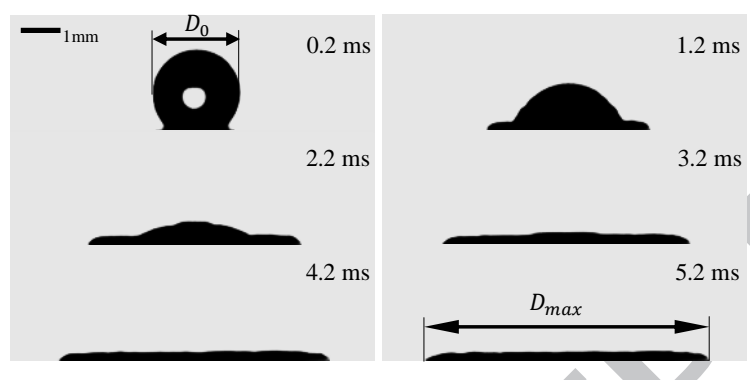

Fig. 5. Photographs of droplet spreading on porous surfaces $\left(W e=31, T_{S}=200^{\circ} \mathrm{C}\right)$

Contact angles were measured during spreading of the droplets using the LB-ADSA method (Stalder et al., 2010). An example of measuring the contact angle is shown in Figure 6.

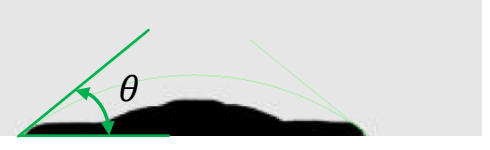

Fig. 6. Measurement of the contact angle (time $=2.2 \mathrm{~ms}, W e=31, T_{s}=200{ }^{\circ} \mathrm{C}, \theta=37.6^{\circ}$ ) 


\subsection{Results and discussion}

Impact regimes were obtained for droplet impact on the cordierite surface for 128 experimental measurement points across the range of droplet impact Weber number and surface temperature conditions.

Figure 7 shows typical recorded images of the droplet impact behaviour for the various impact regimes visualised for the droplet-porous surface interaction. To aid the visualisation of the shape of the droplets and liquid films during the early stages of the droplet impact experiments, recorded videos of droplet impact were image processed using edge detection.

1) Spread regime: The inertia of the droplet causes it to spread out on impact to form a thin and dynamic fluid film in a similar way to the droplet impaction on impermeable surfaces, at low surface temperature. For the porous surface, spreading of the droplet is accompanied by permeation of liquid into the porous surface. The pores close to the impact interface are saturated with fluid so that any liquid remaining on the porous surface forms a thin liquid film (Reis et al., 2004). This regime occurs when $T_{s} \leq 200^{\circ} \mathrm{C}(15 \leq W e \leq 500)$ and $T_{s} \leq 250^{\circ} \mathrm{C}(W e \leq 283)$, which are defined as the pure adhesion temperature in the Bai-Gosman regime map (Bai and Gosman, 1995) and the Leidenfrost temperature in the Staat et al. regime map (Staat et al., 2015).

Compared to the spread regime for impermeable surfaces, the pure adhesion temperature on the porous surface is higher (> $100^{\circ} \mathrm{C}$ - the boiling temperature of water). This indicates that there is very limited boiling even when the surface temperature is above the saturation temperature. The observed smooth surface of the droplet, as shown in Figure 7, provides further evidence that there are very few bubbling events (i.e. water evaporation).

Furthermore, the other two impact regimes for droplet impact on impermeable surfaces (Bai and Gosman, 1995), named 'stick', and 'splash' in Figure 1.a., when the surface temperature is below the pure adhesion temperature, do not appear during the current experiments for Weber number up to 500. This can be due to the strong capillary effect of the porous structure which absorbs a large amount of kinetic energy from the spreading liquid film to prevent it splash away from the surface.

2) Boiling-induced break-up regime: This regime occurs when the surface temperature increases beyond the pure adhesion temperature $\left(T_{S}>250^{\circ} \mathrm{C}\right)$ and the Weber number is relatively low $(\mathrm{We} \leq 102)$. In this regime, boiling starts to occur almost instantaneously when the falling droplet reaches the hot surface. As the droplet further compresses the generated vapour layer due to the inertial effect, the compressed vapour layer will provide reaction forces to the droplets and and resists the permeation of liquid into the porous surface (i.e. reduced capillary effects due to smaller contact area to make the surface less permeable). The small Weber number indicates the droplet has inadequate initial kinetic energy to overcome the surface tension effect and trigger the breakup phenomena (i.e. splash). As a result, the droplet will spread out to form a thin liquid film as in the spread regime. The consequent bubbling events during the boiling process in this regime serve to destabilise the liquid film through the bubble formation and bursting process, which produces numerous secondary droplets. The majority of the secondary 
bubbles are generated after the liquid film spreads to size close to the maximum radius. This indicates that the liquid must advance almost to its maximum extent to heat up the droplet to saturation temperature.

Another distinct feature in this regime is the recoil phenomenon. Unlike the recoil phenomenon observed during the impact of droplet on unheated surfaces where the recoil only occurs during the liquid receding process, the recoil of droplets on heated porous surfaces can take place either during the liquid advancing or receding stage. As explained by Mao et al. (Mao et al., 1997), the recoil on unheated surface occurs when the droplet has high enough initial kinetic energy to spread beyond the distance defined by the static wetting condition of a droplet on the surface so that the surface tension force starts to pull the triple contact line inwards. If the kinetic energy gained through this pull-back process is high enough to push the liquid in the middle upwards, the recoil phenomena, which features a vertical liquid column known as the Worthington jet (Worthington, 1908), occurs. Therefore, the recoil regime on unheated impermeable surfaces is defined by a threshold Weber number. However, on the heated surfaces in current experiments, the recoil regime can only be defined by the combination of surface temperature and the Weber number. This indicates that the recoil phenomena on the heated surface are triggered by the interplay between the capillary force and the reaction force due to liquid evaporation.

\begin{tabular}{|c|c|c|c|c|c|}
\hline & \multirow{2}{*}{ Spread } & \multicolumn{2}{|c|}{ Boiling-induced break-up } & \multicolumn{2}{|c|}{ Boiling-induced splash } \\
\hline & & No recoiling & $\begin{array}{l}\text { Advancing } \\
\text { recoiling }\end{array}$ & $\begin{array}{c}\text { With } \\
\text { continuous liquid film }\end{array}$ & $\begin{array}{c}\text { With } \\
\text { broken liquid film }\end{array}$ \\
\hline & $W e=31, T_{S}=50^{\circ} \mathrm{C}$ & $W e=31, T_{S}=320^{\circ} \mathrm{C}$ & $W e=31, T_{S}=340^{\circ} \mathrm{C}$ & $W e=350, T_{S}=320^{\circ} \mathrm{C}$ & $W e=500, T_{S}=450^{\circ} \mathrm{C}$ \\
\hline Time & & 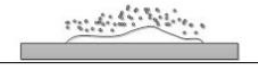 & 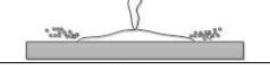 & S & $\mathrm{m}^{\infty}$ \\
\hline $0 \mathrm{~ms}$ & (०) & 8 & (2) & 9 & (1) \\
\hline $1 \mathrm{~ms}$ & & & $-\infty$ & $\therefore-$ & DOn- \\
\hline $2 \mathrm{~ms}$ & & & 3 & Dominiminciners. & 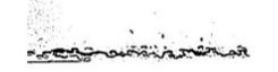 \\
\hline $3 \mathrm{~ms}$ & & & & 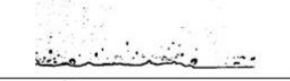 & 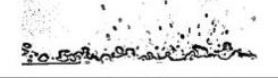 \\
\hline $4 \mathrm{~ms}$ & & & & $\therefore$ & s \\
\hline $5 \mathrm{~ms}$ & & & $\therefore$ & -10 & 管 \\
\hline $6 \mathrm{~ms}$ & & प्य & $\begin{array}{l}\because \quad B \\
\therefore\end{array}$ & $\therefore \quad \therefore \quad$ & $\therefore \quad 100$ \\
\hline
\end{tabular}

Fig. 7. Droplet impact regimes of droplet-porous surface interaction. Images are from experiments and are post-processed using an edge detection algorithm.

2.1) Advancing recoiling regime: This regime only occurs at low Weber number ( $\mathrm{We} \leq 53)$ and medium surface temperature $\left(350^{\circ} \mathrm{C} \leq T_{S} \leq 420^{\circ} \mathrm{C}\right)$. The occurrence of this regime can be explained by considering the interplay between the downwards 
momentum of the droplet and upwards reaction force from the evaporation process. At low temperature, the evaporation rate is relatively low, so the initial downwards momentum dominates over the reaction force from the production and compression of the vapour layer. As temperature rises, the reaction force increases and overcomes the initial downward momentum, triggering the recoil phenomenon. The appearance of the vertical liquid column is usually accompanied by a breakup process of the column due to the well-established Rayleigh-Plateau instability. As the temperature further increases, the high initial evaporation rate produces a stable vapour layer, which reduces the heat transfer rate and the evaporation rate, hence reducing the reaction force. As a result, the downward momentum becomes dominant again and suppresses the recoil phenomenon during the advancing stage.

3) Boiling-induced splash regime: This regime occurs at medium to high surface temperature $\left(T_{s} \geq 300^{\circ} \mathrm{C}\right)$ and high Weber number (We $\geq 80$ ). Similar to the boiling-induced break-up regime, boiling occurs consistently during the impingement process. Therefore, the capillary effects of the porous substrate are reduced due to constant liquid evaporation. Compared to the boiling-induced break-up regime, droplets in this regime have a high enough initial kinetic energy to overcome the surface tension force when impinging on the surface and trap a continuous or broken vapour layer. As a result, the splash phenomena have a similar appearance to those observed for droplet impacts on impermeable surfaces (Bai and Gosman, 1995). Two different types of secondary droplets are generated in this regime. The first type of secondary droplets is similar to those of the boiling-induced breakup regime, which are very fine droplets generated after the liquid film reaches the maximum spreading distance. They are most likely generated due to the bubble formation and bursting induced instability. The second type of droplets is much bigger and generated shortly after the initial impact. These droplets are generated due to Rayleigh-Plateau instability of the rim surrounding the liquid film (Josserand and Zaleski, 2003). These two types of secondary droplets behave quite differently on the high-temperature heated surface. The first type of fine droplets gains a sufficient amount of kinetic energy through the Leidenfrost phenomenon to be accelerated to fly away. The second type of bigger droplets tends to float and translate above the surface due to their higher weight.

This regime can be further divided into two sub-regimes: a splash regime with continuous liquid film, and a splash regime with broken liquid film.

3.1) Splash regime with continuous liquid film: this regime occurs at medium Weber number $\left(80 \leq \mathrm{We} \leq 283\right.$ at $T_{s} \geq 340^{\circ} \mathrm{C}$ and $152 \leq \mathrm{We} \leq 400$ at $T_{s}=300-320^{\circ} \mathrm{C}$ ). Shortly after the initial impingement, the spreading liquid film becomes highly unstable near the edge and quickly breaks up generating numerous droplets which fly away at a small angle to the surface. This could be a sign of a noticeable increase in the evaporation rate so that the compression of the generated vapour layers interacts with the surface tension effect to trigger the Rayleigh-Plateau instability of the thin liquid film to produce those secondary droplets (Josserand and Zaleski, 2003). Away from the edge, the liquid film is still continuous and shows a wavy structure due to the interaction between the capillary wave and growing bubbles. 
3.2) Splash regime with broken liquid film: this regime occurs at high Weber number (We $\geq 350$ at $T_{s} \geq 340^{\circ} \mathrm{C}$ and $\mathrm{We} \geq$ 450 at $T_{S}=300-320^{\circ} \mathrm{C}$ ). Shortly after the intial impingement, the spreading liquid film becomes highly unstable across the whole spreading area and quickly breaks up to produce large amount of droplets on the surface. Some of the droplets will later on merge together to form a continuous liquid film and other move away separately.

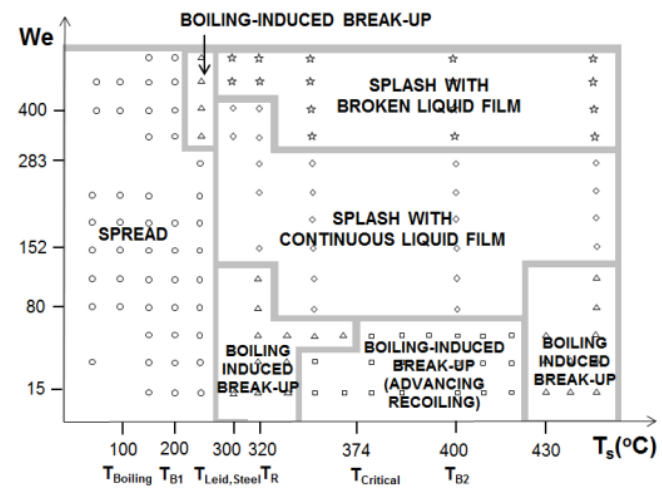

Fig. 8. Droplet impact regimes and transition conditions for a porous surface $\left(\mathrm{T}_{\mathrm{Boilin}}: 100^{\circ} \mathrm{C}\right.$ (water), $\mathrm{T}_{\mathrm{B} 1}: 200^{\circ} \mathrm{C}$ the pure adhesion temperature, $\mathrm{T}_{\text {Leid,Steel: }} 280-325^{\circ} \mathrm{C}$ (Bernardin and Mudawar, 1999), $\mathrm{T}_{\mathrm{R}}: 320^{\circ} \mathrm{C}$ (approximately equal to Leidenfrost temperature for impermeable surfaces), $\mathrm{T}_{\text {Critical }}: 374^{\circ} \mathrm{C}$ (water), $\mathrm{T}_{\mathrm{B} 2}: 400^{\circ} \mathrm{C}$ (a high temperature peak in spreading ratio))

These experiments have revealed the existence of three different regimes (together with three sub-regimes) of impingement behaviour for a $2.2 \mathrm{~mm}$ water droplet impacting on a heated cordierite porous surface. Figure 8 shows a regime transition map for the present data set showing different regions: spreading regime (circles), boiling-induced break-up (triangles), boilinginduced break-up with advancing recoiling (squares), splash with continuous liquid film (diamonds) and splash with continuous liquid film (stars). Lines in the figure indicate the boundaries between different impact regimes. It should be noted that the transition between different regimes is continuous, so the threshold conditions defined in this paper are not sharp changes, but rather diffuse, and mixed phenomena in two adjacent regimes can occur simultaneously in conditions close to the identified threshold condition.

Comparing with the Bai-Gosman map (Bai and Gosman, 1995) which was developed on impermeable surfaces, it is clear that the droplet impact regimes on the porous surface are quite different. One of the main differences is the absence of the 'stick' and the 'splash' regimes for surface temperature lower than the pure adhesion temperature, and the 'rebound' regime at high temperature. The absence of these regimes is mainly due to the capillary effects of the porous substrate so the detailed modelling of the impact behaviour will need to take into account this capillary effect. The other major difference is the combinations of threshold surface temperature and Weber number which define the boundaries of different regimes for droplet impacts on heated porous surfaces. These differences highlight the importance of understanding the validity of those well- 
established critical temperatures, such as the boiling temperature and the Leidenfrost temperature, on the porous surfaces. On impermeable surfaces, if the surface temperature is larger than the Leidenfrost point (LFP), the droplet rebounds off the surface after the impact. However, the rebound does not occur after the droplet impact on the porous surface, even if the porous surface temperature $\left(450^{\circ} \mathrm{C}\right)$ is much higher than the Leidenfrost point on impermeable surfaces $\left(280^{\circ} \mathrm{C}-325^{\circ} \mathrm{C}\right.$, steel surface) (Bernardin and Mudawar, 1999). As noted earlier, a contributing factor for this difference is the significant local cooling for the cordierite surface, due to the low thermal conductivity, compared with steel surfaces.

An analytical study of LFP has been developed by considering a droplet to be suspended by its own vapour due to the evaporation on both impermeable surfaces (Gottfried and Bell, 1966) and porous surfaces (Avedisian and Koplik, 1987). The weight of the droplet is counterbalanced by an upward force produced by the pressure distribution in the vapour film at the base of the droplet surfaces (Avedisian and Koplik, 1987). According to their analytical solution the LFP increases with porosity and the maximum porosity for levitation is 0.786 at a surface temperature of $450^{\circ} \mathrm{C}$ (highest surface temperature in this study) and the length scale characteristic of the porous grain of $10 \mu \mathrm{m}$. For the surface temperature of $280{ }^{\circ} \mathrm{C}$ (lowest LFP of impermeable surfaces (Bernardin and Mudawar, 1999)), the maximum porosity for levitation is 0.75 . Therefore, even if the theoretical prediction of LFP of the porous surface has been achieved in this study, there is still no levitation. This might be due to the low thermal conductivity of the cordierite porous substrate in this study, so the surface cools down below the LFP during the initial impact process even if the time-averaged surface temperature is above LFP.

\section{Experimental study of post-impingement spreading characteristic}

This section focuses on the effect of droplet Weber number and surface temperature on the maximum spreading ratio of the spreading liquid film after the impingement. The wetting diameter and contact time of the spreading liquid film are vital for heat transfer processes after droplet impact.

\subsection{Effect of droplet Weber number}

As detailed in the previous section, the dynamics of the spreading liquid film during the liquid advancing phase are similar for both the 'spread' and 'boiling-induced breakup' regimes. In case of the splash regime, the maximum diameter was measured from the continuous liquid film (i.e. ignoring the separated sections of the liquid film, visible in Figure 7). The variation of maximum spreading ratio with Weber number at different surface temperatures is presented in Figure 9 . It is clear that the maximum spreading ratio increases with increasing Weber number. This can be explained by the increase in the initial kinetic energy when the Weber number is increased, which enables the liquid film to spread further. 


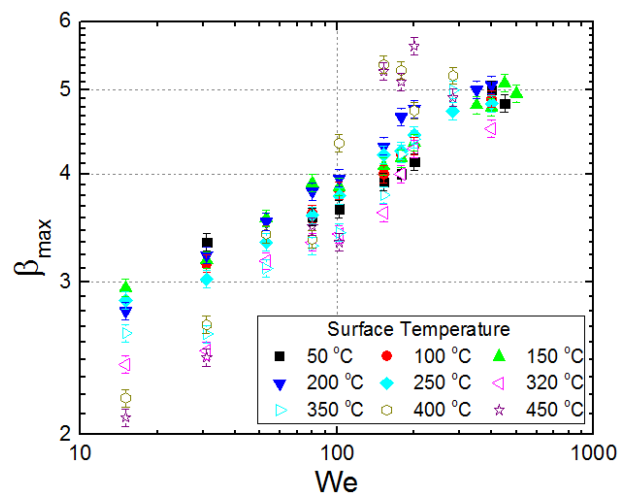

Fig. 9. Maximum spreading ratio versus Weber number at different surface temperatures (log-log plot)

When $T_{s}>250^{\circ} \mathrm{C}$ (open markers), the Weber number plays a more important role to set the boundary between the break-up regime' and the 'splash regime', as detailed in previous session. In addition, the boiling phenomena becomes more important for $T_{s}>250^{\circ} \mathrm{C}$. As a result, there are strong interactions between the droplet inertial force, the capillary force and the extra forces due to bubble formation and bursting (e.g. the bubble growth inertia force, bubble-induced viscous dissipation and pressure force during bubble bursting). In the 'spread regime' (i.e. $T_{s} \leq 250^{\circ} \mathrm{C}$, solid markers), the amplitude of capillary waves on the liquid film increases with Weber number, as illustrated in Figure 10.

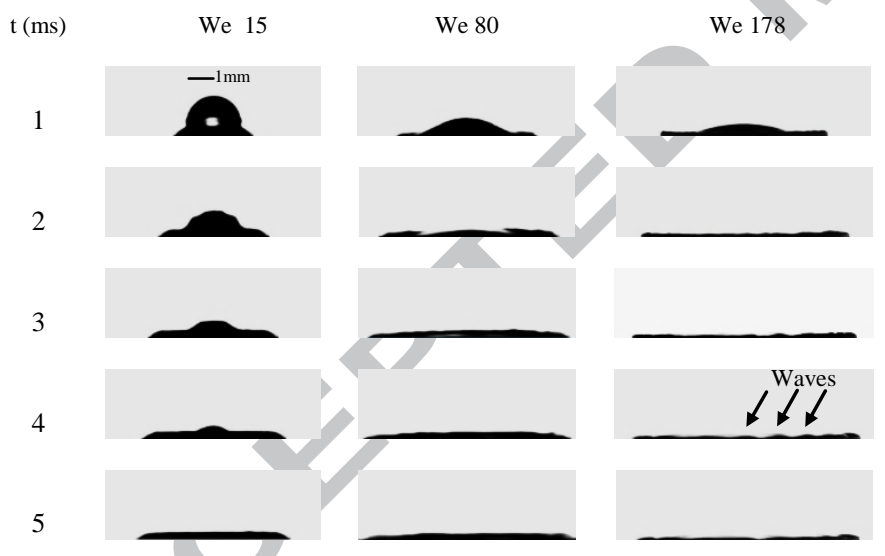

Fig.10. Photographs of droplet spreading on porous surfaces at different $W e\left(T_{S}=150^{\circ} \mathrm{C}\right)$

\subsection{Effect of porous surface temperature}

The effect of surface temperature on the liquid film geometry is illustrated in Figure 11. This shows that bubbling events start to distort the liquid film when $T_{s} \geq 320^{\circ} \mathrm{C}$. 


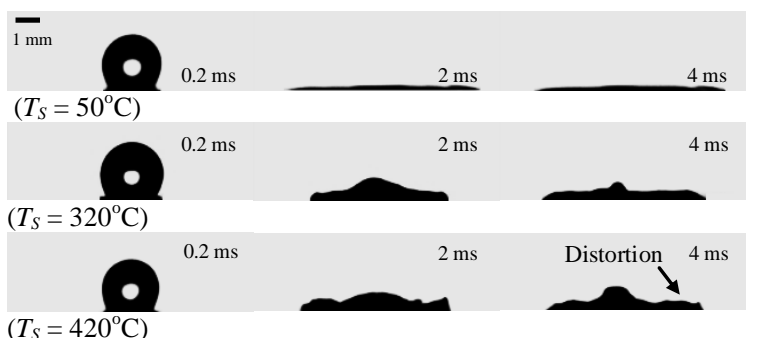

Fig. 11. Photographs of droplet spreading on porous surfaces at different surface temperatures $(W e=31)$

Figure 12 plots the maximum spreading ratio versus surface temperature at different Weber numbers. At surface temperatures $\leq$ $200^{\circ} \mathrm{C}$, there is generally little variation of maximum spreading ratio with surface temperature. The transition temperature from the spread regime to other regimes is near $250^{\circ} \mathrm{C}$. Considering the negligible boiling in the 'spread regime', it is likely that the maximum spreading ratio is insensitive to droplet heating as long as boiling does not occur. When the $T_{S} \geq 320^{\circ} \mathrm{C}$, the maximum spreading ratio rapidly increases with surface temperature for $\mathrm{We}>200$. Together with the liquid film dynamics shown in Figure 11, such a large variation could be due to the strong bubble-film interactions caused by boiling. At small to medium Weber number $(<200)$, most of the spreading ratios increase slightly to a local peak value and then decreases to a local minimum before reaching a highly fluctuation region. At medium Weber number (102 - 200), the peak value occurs at around $200^{\circ} \mathrm{C}$. The small increase in the maximum spreading ratio could be due to the reduced surface tension and viscosity of the liquid film, so less kinetic energy is dissipated and more energy is available for the liquid film to spread outwards. The maximum spread ratio will then reach a peak value when the boiling interrupts the spreading process. As the Weber number increases, the increase in the liquid advection will suppress the bubble nucleation so the boiling occurs at a higher surface temperature, as in convective boiling. Therefore, the temperature where the maximum spreading ratio reaches a local peak value could be a signpost for the boiling process (i.e. bubble nucleation). As the surface temperature further increases, the bubble nucleation occurs more vigorously so will interrupt the spreading process more frequently. As a result, the spreading ratio keeps decreasing until another critical temperature where the bubble nucleation becomes less frequent. Such local minima occur at around $320^{\circ} \mathrm{C}$ consistently regardless of the Weber number. In a typical boiling curve, such a temperature is usually defined as the Leidenfrost temperature. Above $320^{\circ} \mathrm{C}$, the spreading ratio starts to increase until the surface temperature reaches $400^{\circ} \mathrm{C}$ where the spreading ratio reaches a maximum. At surface temperatures above $400^{\circ} \mathrm{C}$, the spreading ratio starts to decrease again. In summary, the data plotted in Figure 12 suggests three critical temperatures for the maximum spreading ratio: (i) the pure adhesion temperature $\left(T_{B I}\right) 200^{\circ} \mathrm{C}$ (ii) at $320^{\circ} \mathrm{C}$ ( $T_{R}$ : approximately equal to Leidenfrost temperature for impermeable surfaces) the spreading ratio is minimum, and (iii) a high temperature peak $\left(T_{B 2}\right)$ in spreading ratio at a surface temperature of $400^{\circ} \mathrm{C}$, where $T_{B 1}, T_{R}$ and $T_{B 2}$ are close to the threshold temperatures when boiling induced break-up and recoiling rebound occur as shown in Figure 8. 


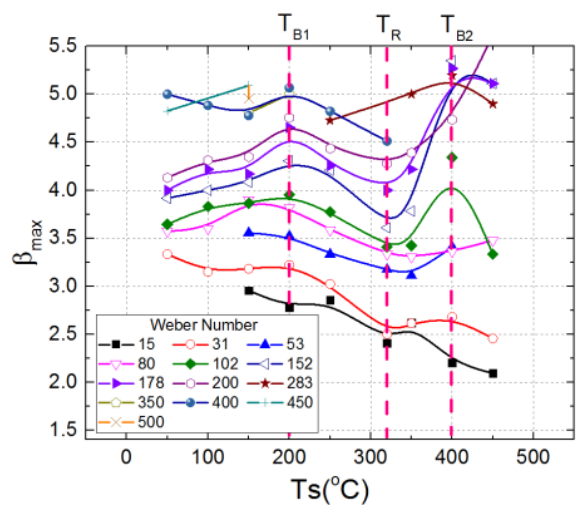

Fig. 12. Maximum spreading ratio versus surface temperature at different Weber numbers

\subsection{Scaling analysis of maximum spreading ratio}

Different scaling laws have been proposed to predict the maximum spreading ratio $\left(\beta_{\max }\right)$ of droplet impact on impermeable surfaces as introduced in the first section. According to the theory of Clanet et al. (Clanet et al., 2004), an impact number $\left(P=W e / R e^{4 / 5}\right)$ was defined to distinguish the impact regimes, such as the viscous regime (high impact velocity, $P>$ $1, D_{\max } \propto R e^{1 / 5}$ ) and the capillary regime (low impact velocity, $P<1, D_{\max } \propto W e^{1 / 4}$ ). The viscous regime assumes that kinetic energy converts to viscous dissipation at the maximum spreading, while the capillary regime assumes that kinetic energy converts to surface energy.

In the present study, $P$ is always smaller than $1(0.02 \leq P \leq 0.35$ with $5 \leq W e \leq 500)$. Therefore, the experimental data for surface temperature, $\mathrm{T}_{\mathrm{s}} \leq 150^{\circ} \mathrm{C}$ are compared with two scalings of the capillary regime as well as Equation $4\left(\beta_{\max } \propto W e^{0.38}\right)$ (Akao et al., 1980) as shown in Figure 13.a. As discussed in section 2, droplet impact at $T_{\mathrm{s}} \leq 150^{\circ} \mathrm{C}$ corresponds to the spread regime (i.e. the heat is transferred only in forms of sensible heat) where the surface temperature has very limited effect on the maximum spreading ratio (the maximum difference between $\beta_{\max , 150^{\circ} \mathrm{C}}$ and $\beta_{\max , 50^{\circ} \mathrm{C}}$ at the same $\mathrm{We}$ is $8 \%$ ). One scaling is obtained based on the momentum balance $\left(\beta_{\max } \propto W e^{1 / 4}\right)$ (Clanet et al., 2004), the other one is obtained using the energy balance $\left(\beta_{\max } \propto W e^{1 / 2}\right)$ (Bennett and Poulikakos, 1993; Eggers et al., 2010). Firstly, it can be seen that the empirical correlation of Akao et al. (Akao et al., 1980) which is widely used in the commercial CFD codes reasonably fits the maximum spreading ratio on impermeable surfaces, but cannot predict $\beta_{\max }$ on porous surfaces. Secondly, the experimental data for the porous surface is not represented adequately by either of the capillary regime scalings $W e^{1 / 4}$ and $W e^{1 / 2}$ especially at the low $W e$. Therefore, we compare our data with scaling of the viscous regime. In the viscous regime, two widely used scalings were obtained based on the energy balance. One scaling is $\beta_{\max } \propto R e^{1 / 5}$ (Re > 100) (Clanet et al., 2004; Laan et al., 2014; Madejski, 1976; Roisman, 2009), the other one is $\beta_{\max } \propto R e^{1 / 4}(W e \gg \sqrt{R e}$ and $W e \gg 12)$ (Pasandideh-Fard et al., 1996). 
In this study, We changes from 30 to $500(47<\sqrt{R e}<95)$. Figure 13.b. shows the comparison between experimental data and different scalings of the maximum spreading ratio for the viscous regime. It can be seen that the existing scalings of the viscous regime cannot predict the $\beta_{\max }$ on porous surfaces.

Regression analysis of the experimental data for the porous surface using the capillary regime assumption $\beta_{\max }=f(W e)$ yielded the following best-fit power law correlation: $\beta_{\max }=1.8 \mathrm{~W} e^{1 / 6}\left(\right.$ Coefficient Of Determination COD $\left.R^{2}=0.95\right)$. The experimental data can be also well fitted by the correlation with Reynolds number: $\beta_{\max }=0.24 R e^{1 / 3}\left(\mathrm{COD} R^{2}=0.95\right)$.

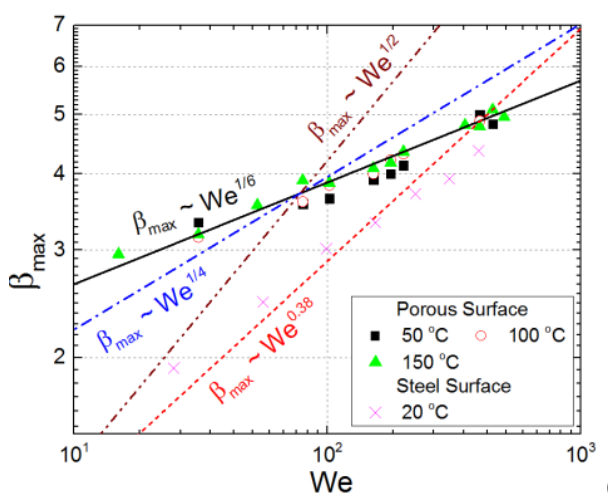

(a)
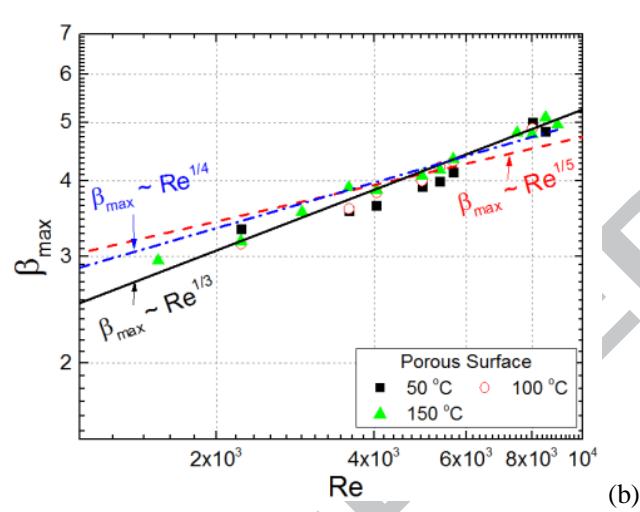

Fig. 13. Comparison between experimental data and scalings of the maximum spreading ratio $\left(\beta_{\max }\right)(\log -\log$ plot) (a) the capillary regime scaling; (b) the viscous regime scaling

In summary, it is found that neither the relationships associated with the existing analysis of the capillary regime nor the viscous regime developed for impermeable surfaces (Clanet et al., 2004; Eggers et al., 2010; Laan et al., 2014) can predict the $\beta_{\max }$ of the porous surface sufficiently accurately over a wide range of We. One of the main reasons is due to differences in the energy balances between droplet impact on impermeable surfaces and porous surfaces. The existing scaling laws were obtained based on studies of droplet impact on impermeable surfaces. To understand the physical process and to predict the maximum spreading ratio, a detailed analysis is carried out to study the energy balance for droplet impacts on porous surfaces. 


\section{Analytical study of post-impingement spreading characteristic}

\subsection{Analytical model}

As discussed in section 2 and evidenced by the results in section 3, the post-impact behaviour of the spreading liquid film is significantly different on a porous substrate. To obtain an accurate estimate of the dynamic spreading of the droplet impact on a porous surface, an energy balance approach was proposed by Joung and Buie (Joung and Buie, 2014). The droplet possesses kinetic energy, potential energy and surface energy just before it contacts the surface. In the energy balance models for impermeable surfaces (Attané et al., 2007; Bechtel et al., 1981; Chandra and Avedisian, 1991; Joung and Buie, 2014; Kim and Chun, 2001; Mao et al., 1997; Pasandideh-Fard et al., 1996) the liquid only possesses surface energy at the instant of maximum spreading. The interaction between the liquid and a porous surface is accounted for by including the matric potential energy associated with the penetration of liquid into the pores of the substrate. During the contact line advancing phase, energy is dissipated by line dissipation (Attané et al., 2007), by viscous dissipation inside the droplet and in the porous region. These processes are illustrated in Figure 14.

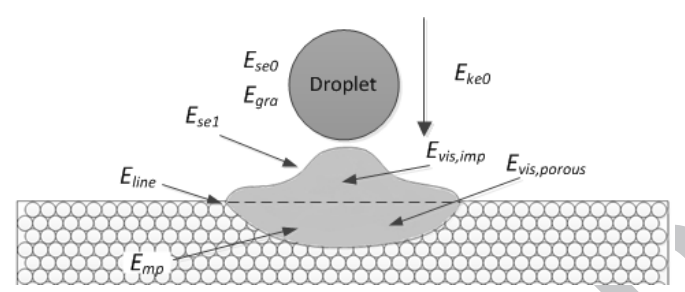

Fig. 14. Energies and dissipations during droplet impact on to a porous surface ( $E_{k e}$ : kinetic energy; $E_{s e}$ : surface energy; $E_{m p}$ : matric potential energy; $E_{g r a}$ : potential energy; $E_{\text {line }}$ : line dissipation; $E_{v i s, i m p}$ : viscous dissipation above the porous surface; $E_{v i s, p o r o u s}$ : viscous dissipation inside the porous surface)

To simplify the analysis, an assumption of cylindrical geometry of the impacting droplet was made. The energy between before and after impact is established as,

$E_{k e 0}+E_{s e 0}+E_{g r a}=$

$E_{s e 1}+E_{m p}+E_{\text {line }}+E_{\text {vis,imp }}+E_{\text {vis,porous }}$

The kinetic energy and surface energy of the droplet before impact are given by (Bechtel et al., 1981; Chandra and Avedisian, 1991; Mao et al., 1997; Pasandideh-Fard et al., 1996),

$E_{k e 0}=\left(\frac{1}{2} \rho U_{0}^{2}\right)\left(\frac{\pi}{6} D_{0}^{3}\right)$

$E_{s e 0}=\pi D_{0}^{2} \sigma$ 
The initial gravitational potential energy is given by,

$E_{g r a}=\rho \frac{\pi}{6} D_{0}^{3} g \frac{D_{0}}{2}$

$\frac{E_{g r a}}{E_{k e 0}}=\frac{D_{0} g}{U_{0}^{2}}=\frac{1}{W e} \frac{\rho g}{\sigma} D_{0}^{2}$

Evaluation of equation 9 for typical experimental parameters shows that the initial gravitational potential energy is much smaller than the kinetic energy $(\leq 2 \%)$ for a $2.2 \mathrm{~mm}$ water droplet for Weber numbers from 5 to 500 , so will be ignored.

The shape of the liquid film at maximum spreading is assumed to be a cylinder. This assumption has been widely used in the literature and Figures 5, 10 and 11 suggest that this is a reasonable approximation. Based on Young's equation (Young, 1805) and surface energy balance on the interface, the surface energy after impact is given by (Chandra and Avedisian, 1991; Ford and Furmidge, 1967; Pasandideh-Fard et al., 1996),

$E_{s e 1}=\frac{\pi}{4} \sigma\left(1-\cos \theta_{a}\right) d_{\max }^{2}$

The surface energy of the side of the assumed cylinder shape of the droplet at maximum spreading is negligible for two reasons: (i) the top surface area of the cylinder is large compared with the side surface area of the cylinder $\left(W e=31, A_{s i d e} / A_{t o p}\right.$ $=0.11$ and $W e=450, A_{\text {side }} / A_{t o p}=0.04$ ); (ii) droplet-porous surface interaction shows a high wetting characteristic (water/cordierite, averaged $\left.\theta_{a}=26^{\circ}, W e=5-500\right)$ comapred with that of impermeable surface (water/steel, averaged $\theta_{a}=$ $\left.103^{\circ}, W e=6-396\right)$. Therefore, the side surface is negligible because of the low ratio of top surface area/ side surface area and the very sharp contact angle.

The matric potential energy is the surface energy inside the wetted porous region. The matric potential energy is controlled by capillary effects associated with the ingress of part of the droplet liquid into the porous medium. As defined by Fredlund and Rahardjo (Fredlund and Rahardjo, 1993), Nitao and Bear (Nitao and Bear, 1996) and Parr et al., (Parr et al., 1981), the expression of the matric potential energy at the moment of maximum spreading is given by:

$E_{m p}=\int_{V_{\text {wet }}}-P_{\text {cap }} d V=\frac{2 \sigma \cos \theta_{\text {cap }}}{r_{\text {pore }}} \frac{\pi}{4} d_{\text {max }}^{2} h_{\text {wet }} \eta_{\text {pore }}$

$\theta_{\text {cap }}$ is the wetting angle of the liquid on the surface of the capillary, $h_{w e t}$ is the wetted depth, $r_{\text {pore }}$ is the pore radius and $\eta_{\text {pore }}$ is the porosity.

In past work, the matric potential has been evaluated by assuming that the whole porous region is wetted (Joung and Buie, 2014). A more general analysis should take into account the possibility of incomplete wetting: the wetted region should represent the wetted pores only rather than the whole porous region. Thus, the wetted depth $h_{\text {wet }}$ is taken to be equal to the minimum of the penetration depth (J B Lee et al., 2016a) and the porous region height is given by,

$h_{\text {wet }}=\min \left(U_{0} \frac{\rho r_{\text {pore }}^{2}}{\mu}, h_{\text {porous }}\right)$ 
The penetration depth was estimated base on the momentum balance of the penetrated liquid in the porous substrate by neglecting capillary penetration (J B Lee et al., 2016a).

The moving line dissipation was defined by Golestanian and Raphaël (Golestanian and Raphaël, 2001) and Snoeijer and Andreotti (Snoeijer and Andreotti, 2013) as:

$E_{\text {line }}=\frac{\mu}{2} \int_{0}^{t_{c}} \int_{\text {line }} \frac{3 \iota}{\theta} U_{R}^{2} d x d t \approx \frac{\mu}{2} \frac{3 \iota}{\theta} U_{0}^{2} \pi d_{\text {max }} t_{c}$

$\iota=\ln \frac{l_{\max }}{l_{\min }}$

where $l_{\max }$ is the droplet diameter $D_{0}, l_{\min }$ is the effective pore diameter $2 r_{\text {pore }}$ and $\theta$ is the contact angle $\left(\theta_{a}\right.$ in this study).

The time $t_{c}$ required for a droplet to reach maximum spreading was obtained by an analytical study of the mass balance reported by (Pasandideh-Fard et al., 1996) and is given by,

$t_{c}=\frac{8}{3} \frac{D_{0}}{U_{0}}$

The estimate of the viscous dissipation in the liquid region is based on the correlation proposed by Chandra and Avedisian (Chandra and Avedisian, 1991),

$E_{v i s}=\int_{0}^{t_{c}} \int_{V} \phi d V d t \approx \phi V t_{c}$

The viscous dissipation function $\phi$ is estimated as follows (Chandra and Avedisian, 1991),

$\phi=\mu\left(\frac{\partial U_{i}}{\partial x_{j}}+\frac{\partial U_{j}}{\partial x_{i}}\right) \frac{\partial U_{i}}{\partial x_{j}} \approx \mu\left(\frac{U_{0}}{\delta}\right)^{2}$

where $\delta$ is a characteristic length; in this case, the boundary layer thickness (Pasandideh-Fard et al., 1996). Details of the estimation of $\delta$ for impermeable surfaces are reviewed in the next section, where an improvement is proposed to describe the viscous dissipation and boundary layer thickness during droplet impact on porous surfaces.

After substitution of Eq. (6)-(17) into Eq. (5) and further simplifications, the following expression for the maximum spreading ratio $\beta_{\max }$ is obtained,

$\left[3\left(1-\cos \theta_{a}\right)+6 f_{m p}+8 \frac{W e}{R e} f_{v i s}\right] \beta_{\text {max }}^{2}+12 \frac{W e}{R e} f_{l} \beta_{\text {max }}-W e-12=0$

with the following dimensionless factors: $f_{m p}$ accounts for the matric potential, $f_{l}$ describes the effect of line dissipation and $f_{\text {vis }}$ represents the viscous dissipation.

$f_{m p}=\frac{\cos \theta_{\text {cap }} h_{\text {wet }} \eta_{\text {pore }}}{r_{\text {pore }}}$

$f_{l}=4 \frac{\iota}{\theta}$;

$f_{\text {vis }}=\frac{D_{0}}{\delta}$ 


\subsection{Improvement of boundary layer thickness description}

Four expressions for the boundary layer thickness $\delta$ and an expression of the residual film thickness at the liquid-impermeable interface have previously been proposed in literature:

$$
\begin{array}{rlr}
\delta_{i m p}=\frac{D_{0}}{\sqrt{\pi}} \sqrt{O h} & \text { (Bechtel et al., 1981) (22) } \\
\delta_{i m p}=h & \text { (Chandra and Avedisian, 1991) (23) } \\
\delta_{i m p}=\frac{2 D_{0}}{\sqrt{R e}} & \text { (Pasandideh-Fard et al., 1996) (24) } \\
\delta_{i m p}=1.88 \sqrt{v t_{c}} & \text { (Roisman, 2009) (25) } \\
h_{r e s}=\frac{0.79 D_{0}}{R e^{2 / 5}} & \text { (Roisman, 2009) (26) }
\end{array}
$$

where $\delta_{i m p}$ is the boundary layer thickness of droplet impact on impermeable surfaces, $O h=\sqrt{W e} / R e, h$ is the height of the lamella at the maximum spreading, $v$ is the kinematic viscosity, $t_{c}$ is the time to the maximum spread $\left(t_{c}=8 D_{0} /\left(3 U_{0}\right)\right)$ and $h_{\text {res }}$ is the residual film thickness. For estimating $\beta_{\max }$, We and $R e$ are calculated based on impact velocity $U_{0}$.

Figure 15 shows the boundary layer thickness predictions as a function of the impact Weber number for a water droplet impact on the cordierite porous surface based on these four expressions. The prediction of Bechtel et al. (Bechtel et al., 1981) is independent of the velocity and, therefore, returns a constant boundary layer thickness (Attané et al., 2007; Kim and Chun, 2001). Chandra and Avedisian's expression (Chandra and Avedisian, 1991) predicts the boundary layer thickness to be the same as the height of the lamella $h . h$ is estimated from the volume conservation of the droplet and the cylindrical geometry assumption $\left(h=2 D_{0}^{3} / 3 d_{\max }^{2}\right) \cdot d_{\max }$ is estimated using the semiempirical relation $\left(d_{\max } \approx 0.87 R e^{1 / 5}-0.40 R e^{2 / 5} W e^{-1 / 2}\right)$ developed and validated by Roisman (Roisman, 2009). The cylindrical geometry assumption has been proved to be reasonable in predicting the maximum spreading characteristics (Kim and Chun, 2001; Roisman, 2009). Roisman's expression (Equation 26) (Roisman, 2009) also predicted the thickness of the lamella (the residual film). Both predictions should be the same in thoery, because they both predict the height of the lamella at the maximum spreading. However, there is much difference between the two preditions. Preditions of $h_{\text {res }}$ are always much smaller than $h$ as shown in Figure 15. The $h_{\text {res }}=$ $0.79 D_{0} / R e^{2 / 5}$ had only been validated for spherical targets rather than flat surfaces (Roisman, 2009). Therefore, we think that $h=2 D_{0}^{3} / 3 d_{\text {max }}^{2}$ is more accurate than $h_{\text {res }}=0.79 D_{0} / R e^{2 / 5}$ in predicting the lamella height of droplets impact on flat surfaces. The Equation 25 of Roisman (Roisman, 2009) predicts the largest value of boundary layer thickness compared with other three predictions at the condition of higher Weber numbers (> 250). The physics of the boundary layer is controlled by the ratio of local to viscous acceleration (Schlichting, 1979). The expression of Pasandideh-Fard et al. (Pasandideh-Fard et al., 1996) predicts an intermediate value of boundary layer thickness at the condition of lower Weber numbers $(<150)$ and the 
smallest value of boundary layer thickness compared with other three predictions at the condition of higher Weber numbers (> $150)$.

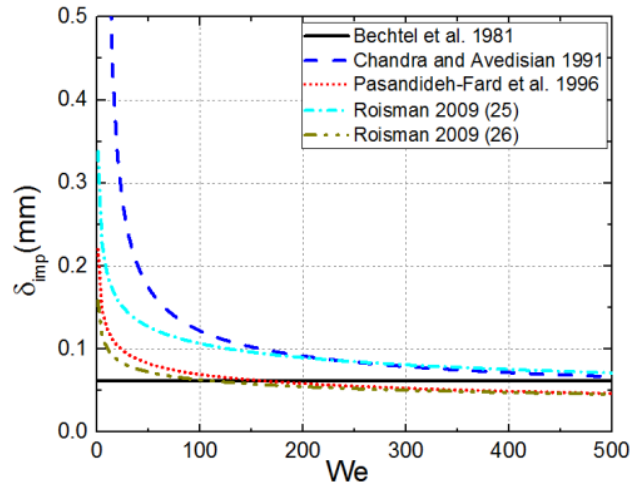

Fig. 15. Estimates of boundary layer thicknesses using Eq. 22-26 based on experiments of droplet impact on the cordierite porous surface

The boundary conditions during droplet impact are different for liquid-impermeable surface interactions and liquid-porous surface interactions. The liquid-impermeable interface can be regarded as a no-slip boundary where the velocity is zero. However, the liquid-porous interface is a slip boundary, and the interface velocity is larger than zero (Goharzadeh et al., 2005; Morad and Khalili, 2009).

Figure 16 shows comparisons of the measured spreading ratios $\left(\beta=D_{n} / D_{0}\right)$ and non-dimensional spreading velocities $\left(U_{i} / U_{0}\right)$ on a steel surface and on the porous surface at the interface. $U_{i}$ is defined as,

$U_{i}=\frac{D_{n-1}-D_{n}}{t_{n-1}-t_{n}}$

where $U_{i}$ is the transient spreading velocity calculated using the spreading diameter $D_{n}$ at time $t_{n}, n$ is the number of time steps. The spreading rate of droplet impact on the porous surface is always higher than that on a stainless-steel surface for different We as shown in Figure 16a. For comparison, evolution of $U_{i} / U_{0}$ are shown in Figure 16b. The spreading velocity of droplet impact on the porous surface is higher than that on the stainless steel in the figure, because the spreading fluid layer has to stick to an impermeable surface $\left(U_{k}=0\right)$ and slips on a porous surface $\left(U_{k} \neq 0\right)$, where $U_{k}$ is the speed of the fluid at the porous/liquid interface. Hence the shear stress on the fluid layer is lower when it spreads over a porous surface, so it can spread further and faster. At $W e \approx 100$, the spreading velocities of both surfaces are almost the same as the early stage $\left(t /\left(D_{0} / U_{0}\right)\right.$ 1). Ratio of $U_{i} / U_{0}$ of both surfaces changes from 1.24 to $1.87\left(1<t /\left(D_{0} / U_{0}\right)<2\right)$. At $W e \approx 400$, ratio of $U_{i} / U_{0}$ of both surfaces changes from 1.07 to $1.67\left(1<t /\left(D_{0} / U_{0}\right)<3\right)$. The smaller difference of $\beta$ at larger We appears to be is associated with the fact that the difference of the spreading velocity becomes smaller with increasing $W e$. It can be seen that $U_{i} / U_{0}$ increases with We, which agrees with the experimental data of Goharzadeh et al. (Goharzadeh et al., 2005). 


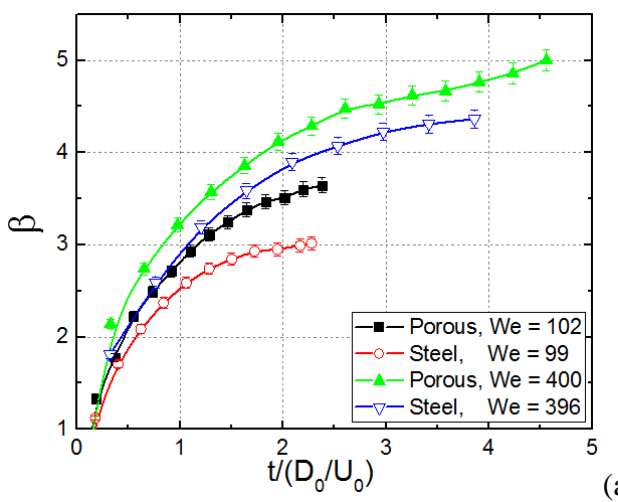

(a)

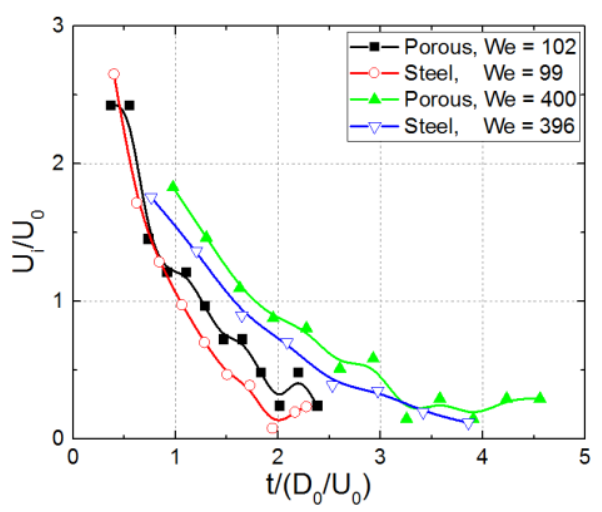

(b)

Fig. 16. Evolution of $\beta$ (a) and $U_{i} / U_{0}$ (b) during droplet impact on a stainless steel surface (water droplet, $D_{0}=1.8 \mathrm{~mm}$, ambient conditions) and a porous surface (water droplet, $D_{0}=2.2 \mathrm{~mm}, 50^{\circ} \mathrm{C}$ porous surface)

The total boundary layer thickness is equal to the boundary layer thickness above the droplet-porous interface plus the boundary layer thickness inside the porous region, as is shown in Figure 17. To improve the modelling of viscous dissipation above and below the droplet-porous interface, an assumption has been made in this paper based on studies (Goharzadeh et al., 2005; Le Bars and Worster, 2006) of the transition layer thickness at a fluid-porous interface. The maximum velocity of the fluid outside the boundary layer is the initial impact velocity and the minimum velocity of the boundary layer inside the porous region is zero. The thickness $\delta_{\text {porous }}$ of the transition layer inside the porous region is of the order of the porous grain diameter (Goharzadeh et al., 2005; Morad and Khalili, 2009). It was also found that the Reynolds number and the fluid height over the porous surface have little effect on the transition layer thickness (Goharzadeh et al., 2005; Morad and Khalili, 2009). 


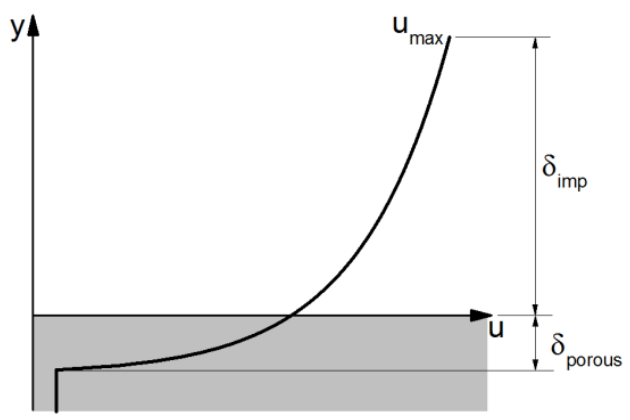

Fig. 17. Boundary layer thicknesses of viscous dissipation inside droplet and porous region

The total viscous dissipation above and below the droplet-porous interface based on the improvement of the boundary layer description can be estimated by,

$\delta_{\text {total }}=\delta_{\text {imp }}+\delta_{\text {porous }}$

$V=V_{\text {imp }}+V_{\text {porous }}=\frac{\pi}{4} d_{\text {max }}^{2} \delta$

$E_{\text {vis }}=E_{\text {vis,imp }}+E_{\text {vis,porous }}=\phi V t_{c}$

$=\mu\left(\frac{U_{0}}{\delta_{\text {total }}}\right)^{2} \frac{\pi}{4} d_{\text {max }}^{2} \delta_{\text {total }} \frac{8}{3} \frac{D_{0}}{U_{0}}$

Equation 24 of Pasandideh-Fard et al. (Pasandideh-Fard et al., 1996) was used in this work to estimate the boundary layer thickness $\delta_{i m p}$ in this study. A number of studies (Jae Bong Lee et al., 2016; Pasandideh-Fard et al., 1996; Visser et al., 2015) have reported that the boundary layer thickness obtained by Equation 24 is of the same order of magnitude as that obtained by CFD simulations. Value of $\delta_{\text {porous }} / \delta_{\text {imp }}$ changes from 0.14 to $0.43(W e=5-500)$ for a water droplet impact on the cordierite porous surface.

\subsection{Prediction of the maximum spreading}

Table 2 shows properties of droplets and porous surfaces in this study $\left(T s \leq 150^{\circ} \mathrm{C}\right)$ and published papers (ambient conditions) (Joung and Buie, 2014; J B Lee et al., 2016a). For our data of droplet impact on the porous surface, the average terminal advancing contact angle $\theta_{a}$ at $W e=5-500$ is $26 \pm 1^{\circ}$ at a surface temperature of $50^{\circ} \mathrm{C}$. 
Table 2. Properties of droplets and porous surfaces

\begin{tabular}{|c|c|c|c|c|c|c|c|c|c|}
\hline $\begin{array}{l}\text { Droplet/ } \\
\text { Surface }\end{array}$ & $\begin{array}{c}D_{0} \\
(\mathrm{~mm})\end{array}$ & We & $\theta_{a}$ & $\theta_{\text {cap }}$ & Porosity & $\begin{array}{l}\text { Effective } \\
\text { pore radius } \\
(\mu \mathrm{m})\end{array}$ & $\begin{array}{c}\text { Effective } \\
\text { Grain radius } \\
(\mu \mathrm{m})\end{array}$ & $\begin{array}{c}\text { Layer } \\
\text { thickness } \\
(\mu \mathrm{m})\end{array}$ & Ref. \\
\hline Water/Cordierite & 0.0022 & $5-500$ & 26 & $85.5^{*}$ & $0.5^{* *}$ & 6 & 10 & 200 & Present \\
\hline Water/Titania & 0.0028 & $73-374$ & 2.6 & 86.7 & $0.5^{*}$ & 10.6 & 10.6 & 8.6 & $\begin{array}{c}\text { (Joung and Buie, } \\
\text { 2014) }\end{array}$ \\
\hline Ethanol/Titania & 0.0022 & 149 & 2.9 & 77.6 & $0.5^{*}$ & 8.85 & 8.85 & 9.5 & $\begin{array}{c}\text { (Joung and Buie, } \\
\text { 2014) }\end{array}$ \\
\hline $\begin{array}{c}\text { Ethylene } \\
\text { glycol/Titania }\end{array}$ & 0.0028 & 772 & 7.4 & 75.2 & $0.5^{*}$ & 28 & 28 & 10.5 & $\begin{array}{c}\text { (Joung and Buie, } \\
2014)\end{array}$ \\
\hline $\begin{array}{c}60 \% \\
\text { Glycerol+40\% } \\
\text { Water/ Titania }\end{array}$ & 0.003 & 402 & 5.7 & 82.2 & $0.5^{*}$ & 25 & 25 & 10.5 & $\begin{array}{c}\text { (Joung and Buie, } \\
\text { 2014) }\end{array}$ \\
\hline $\begin{array}{c}90 \% \\
\text { Glycerol+10\% } \\
\text { Water/ Titania }\end{array}$ & 0.0029 & 327 & 19.6 & 83.7 & $0.5^{*}$ & 21 & 21 & 10.5 & $\begin{array}{l}\text { (Joung and Buie, } \\
\text { 2014) }\end{array}$ \\
\hline Water/Savonnieres & 0.002 & $1.6-137$ & 70 & $87 *$ & 0.56 & 100 & 10.3 & $500^{*}$ & $\begin{array}{l}\text { (J B Lee et al., } \\
2016 a)\end{array}$ \\
\hline
\end{tabular}

Figure 18 shows that the developed analytical model for predicting maximum spreading of droplet impact on porous surface, which ignores the effect of heat transfer and change of temperature, match well with the measured data for surface temperature up to $250^{\circ} \mathrm{C}$ in this paper and published data (ambient conditions) (Joung and Buie, 2014; J B Lee et al., 2016a). The maximum difference between $\beta_{\max , 150^{\circ} \mathrm{C}}$ and $\beta_{\max , 50^{\circ} \mathrm{C}}$ at the same We is $8 \%$. However, the maximum differece between $\beta_{\max , 200^{\circ} \mathrm{C}}$ and $\beta_{\max , 50^{\circ} \mathrm{C}}$ at the same We is $14 \%$. As discussed in section 2 and 3, this corresponds to the spread regime (i.e. the heat is transferred only in forms of sensible heat) where the surface temperature has very limited effect on liquid properties ((e.g. viscosity)) and the maximum spreading ratio. Therefore, the developed model is capable of predicting $\beta_{\max }$ at $T s \leq 150{ }^{\circ} \mathrm{C}$ (the effect of changing liquid properties on $\beta_{\max }$ is negligible).

Good agreement between the predictions and the experimental data was found over a wide range of Weber number (1.6 - 500). The level of agreement decreases somewhat at lower values of $\beta_{\max }$. A single outlier occurs where $\beta_{\max }=2$ was measured by Joung and Buie (Joung and Buie, 2014) for a $90 \%$ glycerol/10\% water droplet. The droplet viscosity of this data point is 0.164 $\mathrm{Pa} \cdot \mathrm{s}$, whereas the droplet viscosity of other points is from 0.0009 to $0.016 \mathrm{~Pa} \cdot \mathrm{s}$. Overestimation of viscous dissipation for such high viscosity droplets is likely to be the cause of the underestimate of the maximum spreading in this case. The description of the boundary layer thickness and wetted region inside the porous surface may need to be reconsidered for high viscous liquid droplets at low impact kinetic energy. 


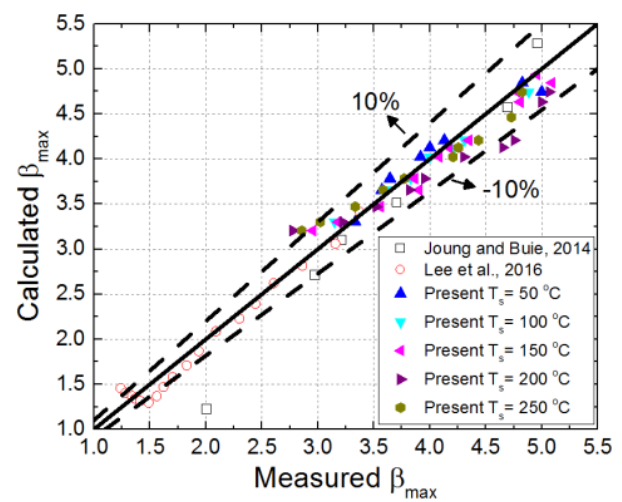

Fig. 18. Comparison of the predictions of maximum spreading with the experimental data in this paper $\left(T s \leq 250{ }^{\circ} \mathrm{C}\right)$ and the literature (ambient conditions) (Joung and Buie, 2014; J B Lee et al., 2016a) for droplet impact on porous surfaces

Energy budgets for the liquid on an impermeable surface (water droplet, $D_{0}=1.8 \mathrm{~mm}$, stainless steel surface, ambient condition, measured $\theta_{a}=103 \pm 1^{\circ}$ ) and a porous surface (cordierite surface) at the maximum spreading are shown in Figure 19. The relative size of each of the terms contributing to the energy at maximum spreading was found by computing the ratio of each energy contribution and the sum of the kinetic energy and surface energy of the droplet before impact. The energy balance of droplet impact on impermeable surfaces is given by (Chandra and Avedisian, 1991; Pasandideh-Fard et al., 1996),

$E_{k e 0}+E_{s e 0}=E_{s e 1}+E_{v i s, i m p}$

The gravitational potential energy and line dissipation were assumed to be negligible. The model (Equation 31) shows good agreement compared to experimental data for $\beta_{\max }$ of droplet impact on impermeable surfaces (Pasandideh-Fard et al., 1996; Ukiwe and Kwok, 2005). The differences in the energy balance between impermeable surfaces (Equation 31) and porous surfaces (Equation 5) are the energy and dissipations terms that are specific to porous surfaces.

Figure 19a shows proportions of different energy terms of droplet impact on the stainless steel surface. The proportions of different energy contributions in Figure 19a have been compared with results of droplet impact on impermeable surfaces by Wildeman et al. (Wildeman et al., 2016). At $(W e=30, R e=1000)$ and $(W e=300, R e=1000$ ), proportions of viscous dissipation are 0.38 and 0.78 in the literature (Wildeman et al., 2016). The proportions of viscous dissipation at the same We become closer with increasing $\operatorname{Re}(8 \%$ decrease for $R e$ changes from 500 to 1000 at $W e=300$ ) in the literature (Wildeman et al., 2016). Our data show that proportions of viscous dissipation are 0.41 at $(W e=30, R e=2190)$ and 0.8 at $(W e=300, R e=$ 6824). By comparison, energy terms of our data are thought to represent the energy distribution correctly.

Figure $19 \mathrm{~b}$ shows proportions of different energy terms of droplet impact on the porous surface. It is evident that viscous dissipation inside droplet and porous region and matric potential dominate the droplet spreading process. At the lower Weber numbers (5 - 50), surface energy and line dissipation are larger than $10 \%$ of the total energy. However, at higher Weber number 
(> 280), surface energy and line dissipation only possess $5 \%$ of the total energy. The gravitational potential energy at the maximum spreading is negligible $(\leq 4 \%)$.

By comparing energy budget between impermeable surface and porous surface, there are at least three differences: (i) about one-third of the total energy loss is associated with the matric potential for the porous surface; (ii) more viscous dissipation of the impermeable surface than that of the porous surface at $W e \geq 100$; (iii) surface energy of the porous surface becomes being negligible at $W e>20$, because the terminal advancing contact angle is very $\operatorname{sharp}\left(\theta_{\text {aporous }}=26^{\circ}\right)$.

It can be concluded that the two main reasons for larger maximum spreading ratio of porous surfaces are as follows: (i) less viscous dissipation of droplet impact on porous surfaces; (ii) matric potential contributes to obtaining a larger maximum spreading ratio of porous surface, which is in broad agreement with the findings by Fredlund \& Rahardjo and Miller (Fredlund and Rahardjo, 1993; Miller, 1989).
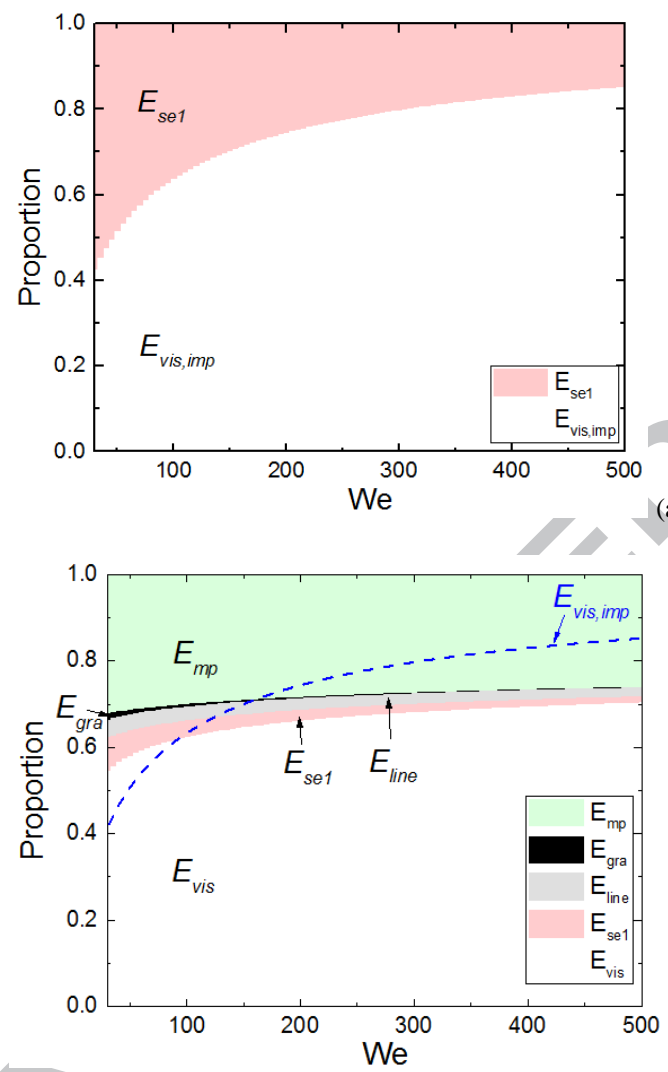

Fig. 19. Energy budgets for an impermeable surface and a porous surface at maximum spreading, normalised by the initial kinetic energy and surface energy. ( $E_{v i s}:$ total viscous dissipation; $E_{v i s, i m p}$ : viscous dissipation of impermeable surfaces; $E_{s e}:$ surface energy; $E_{g r a}:$ gravitational potential energy; $E_{\text {line: }}$ line dissipation; $E_{m p}$ : matric potential energy) 


\section{Conclusion and future work}

Droplet impact on porous surfaces has been investigated experimentally over a wide range of Weber numbers and surface temperatures. A regime map has been developed for the droplet-porous surface interaction to characterise the post-impingement behaviour of the droplet as a function of impact Weber number and surface temperature. Differences of the transition regimes between droplet impacts on impermeable surfaces and porous surfaces are mainly due to the capillary effects of the porous substrate and significant local cooling for the cordierite surface (the low thermal conductivity). The maximum spreading ratio was found to be insensitive to the surface temperature over a wide range of Weber numbers if the surface temperature is below the boiling-induced break-up temperature. It is found that neither the existing capillary regime nor viscous regime identified for droplet impacts on impermeable surfaces (or a combination of these regimes), could describe $\beta_{\max }$ for droplet impact on a porous surface over a wide range of $W e$

An energy balance model was proposed to predict maximum spreading of droplet impact on the porous surface when the effect of surface temperature on maximum spreading is negligible. It included an improved description of the boundary layer thickness to facilitate calculation of viscous dissipation. The other significant improvement is based on the liquid penetration depth and porosity to predict the matric potential energy inside the porous region. The improved model predicting the maximum spreading ratio shows good agreement with the experimental data in this paper and the literature for droplet impact on porous surfaces. Therefore, this model has been shown to have the ability to predict the maximum spreading of droplet impact on porous surfaces.

Energy distributions of both the impermeable surface and the porous surface at the maximum spreading have been studied. It was found that the spreading process after droplet impact on the porous surface is governed by the viscous dissipation and matric potential. Less viscous dissipation of droplet impact on porous surfaces than on impermeable surfaces and the net effect of matric potential give rise to a larger maximum spreading ratio for the porous surface.

The comparison between the measured data and the modelling results shows the effect of heat and mass transfer can be ignored on predicting the maximum spreading ratio when the surface temperature $\leq 150^{\circ} \mathrm{C}$. When the surface temperature is higher than $150^{\circ} \mathrm{C}$, especially in the condition where the effect of boiling becomes essential, the current analytical model needs to take into account the disturbance caused by bubbling events to predict the spreading behaviour. This will be our future work.

\section{Acknowledgements}

We acknowledge the support of the Wolfson School of Mechanical, Electrical and Manufacturing Engineering at Loughborough University. 


\section{References}

Abuku, M., Janssen, H., Poesen, J., Roels, S., 2009. Impact, absorption and evaporation of raindrops on building facades. Build. Environ. 44, $113-124$.

Akao, F., Araki, K., Mori, S., Moriyama, A., 1980. Deformation behaviors of a liquid droplet impinging onto hot metal surface. Trans. Iron Steel Inst. Japan 20, 737-743.

Antonini, C., Bernagozzi, I., Jung, S., Poulikakos, D., Marengo, M., 2013. Water drops dancing on ice: How sublimation leads to drop rebound. Phys. Rev. Lett. 111, 014501.

Araki, K., Moriyama, A., 1980. Theory on deformation behavior of a liquid droplet impinging onto hot metal surface. Trans. Iron Steel Inst. Japan 21, 583-590.

Arnaldo Del Cerro, D., Marín, Á.G., Römer, G.R.B.E., Pathiraj, B., Lohse, D., Huis In 'T Veld, A.J., 2012. Leidenfrost point reduction on micropatterned metallic surfaces. Langmuir 28, 15106-15110. doi:10.1021/la302181f

Attané, P., Girard, F., Morin, V., 2007. An energy balance approach of the dynamics of drop impact on a solid surface. Phys. Fluids $19,12101$.

Avedisian, C.T., Koplik, J., 1987. Leidenfrost boiling of methanol droplets on hot porous/ceramic surfaces. Int. J. Heat Mass Transf. 30, 379393.

Bai, C., Gosman, A.D., 1995. Development of methodology for spray impingement simulation. SAE Pap. 950283.

Bang, B.H., Yoon, S.S., Kim, H.Y., Heister, S.D., Park, H., James, S.C., 2011. Assessment of gas and liquid velocities induced by an impacting liquid drop. Int. J. Multiph. Flow 37, 55-66.

Bechtel, S.E., Bogy, D.B., F.E. Talke, 1981. Impact of a liquid drop against a flat surface. IBM J. Res. Dev. 25, 963-971.

Bennett, T., Poulikakos, D., 1993. Splat-quench solidification: estimating the maximum spreading of a droplet impacting a solid surface. J. Mater. Sci. 28, 963-970.

Bernardin, J.D., Mudawar, I., 1999. The Leidenfrost point: experimental study and assessment of existing models. J. Heat Transfer $121,894$.

Bernardin, J.D., Stebbins, C.J., Mudawar, I., 1997. Mapping of impact and heat transfer regimes of water drops impinging on a polished surface. Int. J. Heat Mass Transf. 40, 247-267. doi:10.1016/0017-9310(96)00119-6

Bertola, V., 2015. An impact regime map for water drops impacting on heated surfaces. Int. J. Heat Mass Transf. 85, $430-437$. doi:10.1016/j.ijheatmasstransfer.2015.01.084

Bolleddula, D.A., Berchielli, A., Aliseda, A., 2010. Impact of a heterogeneous liquid droplet on a dry surface: Application to the pharmaceutical industry. Adv. Colloid Interface Sci. 159, 144-159.

Castanet, G., Liénart, T., Lemoine, F., 2009. Dynamics and temperature of droplets impacting onto a heated wall. Int. J. Heat Mass Transf. 52, 670-679. doi:10.1016/j.ijheatmasstransfer.2008.07.024

Chandra, S., Avedisian, C.T., 1992. Observations of droplet impingement on a ceramic porous surface. Int. J. Heat Mass Transf. 35, 23772388.

Chandra, S., Avedisian, C.T., 1991. On the collision of a droplet with a solid surface. Proc. R. Soc. A Math. Phys. Eng. Sci. $432,13-41$.

Clanet, C., Béguin, C., Richard, D., Quéré, D., 2004. Maximal deformation of an impacting drop. J. Fluid Mech. 517, $199-208$.

Day, J.P., 1996. Substrate effects on light-off-part I thermal energy requirements. SAE Pap. 962074. 
Eggers, J., Fontelos, M.A., Josserand, C., Zaleski, S., 2010. Drop dynamics after impact on a solid wall: Theory and simulations. Phys. Fluids $22,062101$.

Ford, R., Furmidge, C., 1967. Impact and spreading of spray drops on foliar surfaces. Soc Chem Ind Monogr 25, 417.

Fredlund, D.G., Rahardjo, H., 1993. Soil mechanics for unsaturated soils, John Wiley \& Sons, Inc. John Wiley \& Sons. doi:10.1016/02677261(93)90011-F

Goharzadeh, A., Khalili, A., Joørgensen, B.B., 2005. Transition layer thickness at a fluid-porous interface. Phys. Fluids 17, 1-10.

Golestanian, R., Raphaël, E., 2001. Dissipation in dynamics of a moving contact line. Phys. Rev. E. Stat. Nonlin. Soft Matter Phys. $64,31601$.

Gottfried, B.S., Bell, K.J., 1966. Film boiling of spheroidal droplets: Leidenfrost Phenomenon. Ind. Eng. Chem. Fundam. 5, 561 -568.

Graves, R.S., Kollie, T.G., McElroy, D.L., Gilchrist, K.E., 1991. The thermal conductivity of AISI 304L stainless steel. Int. J. Thermophys. 12, 409-415. doi:10.1007/BF00500761

Hahn, D.W., Özışık, M.N., 2012. Heat conduction. Wiley.

Jeong, S.-J., Lee, S.-J., Kim, W.-S., Lee, C.B., 2005. Simulation on the optimum shape and location of urea injector for urea-SCR system of heavy-duty diesel engine to prevent NH3 slip. SAE Pap. 2005-01-3886.

Jia, M., Peng, Z., Xie, M., 2008. Evaluation of breakup models and application to the mixture preparation process for diesel HCCI engines. SAE Pap. 2008-01-0023.

Josserand, C., Thoroddsen, S.T., 2016. Drop Impact on a Solid Surface. Annu. Rev. Fluid Mech. 48, 365-391. doi:10.1146/annurev-fluid$122414-034401$

Josserand, C., Zaleski, S., 2003. Droplet splashing on a thin liquid film. Phys. Fluids 15, 1650-1657.

Joung, Y.S., Buie, C.R., 2014. Scaling laws for drop impingement on porous films and papers. Phys. Rev. E - Stat. Nonlinear, Soft Matter Phys. 89, 13015.

Kendall, G.E., Rohsenow, W.M., 1978. Heat transfer to impacting drops and post critical heat flux dispersed flow. MIT Heat Transf. Lab. Cambridge, Rep. 85694-100.

Kim, H., Truong, B., Buongiorno, J., Hu, L.W., 2011. On the effect of surface roughness height, wettability, and nanoporosity on leidenfrost phenomena. Appl. Phys. Lett. 98. doi:10.1063/1.3560060

Kim, H.Y., Chun, J.H., 2001. The recoiling of liquid droplets upon collision with solid surfaces. Phys. Fluids 13, 643-659.

Kim, W.S., Lee, S.Y., 2014. Behavior of a water drop impinging on heated porous surfaces. Exp. Therm. Fluid Sci. 55, 62-70.

Kruse, C., Anderson, T., Wilson, C., Zuhlke, C., Alexander, D., Gogos, G., Ndao, S., 2013. Extraordinary shifts of the leidenfrost temperature from multiscale micro/nanostructured surfaces. Langmuir 29, 9798-9806. doi:10.1021/la401936w

Kwon, H.M., Bird, J.C., Varanasi, K.K., 2013. Increasing Leidenfrost point using micro-nano hierarchical surface structures. Appl. Phys. Lett. 103. doi:10.1063/1.4828673

Laan, N., De Bruin, K.G., Bartolo, D., Josserand, C., Bonn, D., 2014. Maximum diameter of impacting liquid droplets. Phys. Rev. Appl. 2, 044018.

Le Bars, M., Worster, M.G., 2006. Interfacial conditions between a pure fluid and a porous medium: implications for binary alloy solidification. J. Fluid Mech. 550, 149. 
Lee, J.B., Derome, D., Carmeliet, J., 2016a. Drop impact on natural porous stones. J. Colloid Interface Sci. 469, 147-156.

Lee, J.B., Derome, D., Dolatabadi, A., Carmeliet, J., 2016. Energy budget of liquid drop impact at maximum spreading: numerical simulations and experiments. Langmuir 32, 1279-1288.

Lee, J.B., Radu, A.I., Vontobel, P., Derome, D., Carmeliet, J., 2016b. Absorption of impinging water droplet in porous stones. J. Colloid Interface Sci. 471, 59-70.

Lee, S.Y., Ryu, S.U., 2006. Recent progress of spray-wall interaction research. J. Mech. Sci. Technol. doi:10.1007/BF02916010

Lockyer, T., Reid, B., Hargrave, G., Gaynor, P., Wilson, J., 2015. Optical investigation on the ability of a cordierite substrate mixing de vice to combat deposits in SCR dosing systems. SAE Pap. 2015-01-1039.

Madejski, J., 1976. Solidification of droplets on a cold surface. Int. J. Heat Mass Transf. 19, 1009-1013.

Mao, T., Kuhn, D., Tran, H., 1997. Spread and rebound of liquid droplets upon impact on flat surfaces. AIChE J. 43, 2169-2179.

Marengo, M., Antonini, C., Roisman, I. V., Tropea, C., 2011. Drop collisions with simple and complex surfaces. Curr. Opin. Colloid Interface Sci. doi:10.1016/j.cocis.2011.06.009

Merkel, G. a, Cutler, W. a, Tao, T., Chiffey, A., Phillips, P., Twigg, M. V, Walker, A., Matthey, J., 2003. New cordierite diesel particulate filters for catalyzed and non-catalyzed applications, in: 9th Diesel Engine Emissions Reduction Conference. pp. 1-9.

Miller, F.C., 1989. Matric water potential as an ecological determinant in compost, a substrate dense system. Microb. Ecol. 18, 59-71.

Morad, M.R., Khalili, A., 2009. Transition layer thickness in a fluid-porous medium of multi-sized spherical beads. Exp. Fluids 46, 323-330.

Mundo, C., Sommerfeld, M., Tropea, C., 1998. On the modeling of liquid sprays impinging on surfaces. At. Sprays 8, 625-652.

Naber, J.D., Reitz, R.D., 1988. Modeling engine spray/wall impingement. SAE Pap. 880107.

Nair, H., Staat, H.J.J., Tran, T., van Houselt, A., Prosperetti, A., Lohse, D., Sun, C., 2014. The Leidenfrost temperature increase for impacting droplets on carbon-nanofiber surfaces. Soft Matter 10, 2102-2109.

Ng, B.T., Hung, Y.M., Tan, M.K., 2015. Suppression of the Leidenfrost effect via low frequency vibrations. Soft Matter 11,775-784.

Nitao, J.J., Bear, J., 1996. Potentials and their role in transport in porous media. Water Resour. Res. 32, 225-250.

O’Rourke, P.J., Amsden, A.A., 2000. A spray/wall interaction submodel for the KIVA-3 wall film model. SAE Pap. 2000-01-0271.

Parr, J.F.F., Gardner, W.R.R., Elliott, L.F.F., Papendick, R.. I., Camprell, G.S., 1981. Theory and measurement of water potential, in: Water Potential Relations in Soil Microbio. pp. 1-22

Pasandideh-Fard, M., Qiao, Y.M., Chandra, S., Mostaghimi, J., 1996. Capillary effects during droplet impact on a solid surface. Phys. Fluids 8, $650-659$

Reis, N.C., Griffiths, R.F., Santos, J.M., 2004. Numerical simulation of the impact of liquid droplets on porous surfaces. J. Comput. Phys. 198, 747-770. doi:10.1016/j.jcp.2004.01.024

Rohan, P., Neufuss, K., Matějíček, J., Dubský, J., Prchlík, L., Holzgartner, C., 2004. Thermal and mechanical properties of cordierite, mullite and steatite produced by plasma spraying. Ceram. Int. 30, 597-603.

Roisman, I. V., 2009. Inertia dominated drop collisions. II. An analytical solution of the Navier-Stokes equations for a spreading viscous film. Phys. Fluids 21. doi:10.1063/1.3129283

Roisman, I. V., Rioboo, R., Tropea, C., 2002. Normal impact of a liquid drop on a dry surface: model for spreading and receding. Proc. R. Soc. 
A Math. Phys. Eng. Sci. 458, 1411-1430.

Ryu, S.U., Lee, S.Y., 2009. Maximum spreading of electrically charged droplets impacting on dielectric substrates. Int. J. Multiph. Flow 35, 17.

Schlichting, H., 1979. Boundary-Layer Theory. Springer.

Senda, J., Kanda, T., Ai-roub, M., Farrell, P. V, 1997. Modeling spray impingement considering fuel film formation on the wall. SAE Pap. 970047.

Snoeijer, J.H., Andreotti, B., 2013. Moving contact lines: scales, regimes, and dynamical transitions. Annu. Rev. Fluid Mech. 45, $269-292$.

Staat, H.J.J., Tran, T., Geerdink, B., Riboux, G., Sun, C., Gordillo, J.M., Lohse, D., 2015. Phase diagram for droplet impact on superheated surfaces. J. Fluid Mech. 779. doi:10.1017/jfm.2015.465

Stalder, A.F., Melchior, T., Müller, M., Sage, D., Blu, T., Unser, M., 2010. Low-bond axisymmetric drop shape analysis for surface tension and contact angle measurements of sessile drops. Colloids Surfaces A Physicochem. Eng. Asp. 364, 72-81.

Talari, V., Behar, P., Lu, Y., Haryadi, E., Liu, D., 2018. Leidenfrost drops on micro/nanostructured surfaces. Front. Energy. doi:10.1007/s11708-018-0541-7

Tang, C., Qin, M., Weng, X., Zhang, X., Zhang, P., Li, J., Huang, Z., 2017. Dynamics of droplet impact on solid surface with different roughness. Int. J. Multiph. Flow 96, 56-69.

Tran, T., Staat, H.J.J., Prosperetti, A., Sun, C., Lohse, D., 2012. Drop impact on superheated surfaces. Phys. Rev. Lett. $108,036101$.

Tran, T., Staat, H.J.J., Susarrey-Arce, A., Foertsch, T.C., van Houselt, A., Gardeniers, H.J.G.E., Prosperetti, A., Lohse, D., Sun, C., 2013.

Droplet impact on superheated micro-structured surfaces. Soft Matter 9, 3272.

Ukiwe, C., Kwok, D.Y., 2005. On the maximum spreading diameter of impacting droplets on well-prepared solid surfaces. Langmuir 21, 666673.

Valášková, M., Martynková, G., 2009. Preparation and characterization of porous cordierite for potential use in cellular ceramics. Chem. Pap. $63,445-449$.

Visser, C.W., Frommhold, P.E., Wildeman, S., Mettin, R., Lohse, D., Sun, C., 2015. Dynamics of high-speed micro-drop impact: numerical simulations and experiments at frame-to-frame times below $100 \mathrm{~ns}$. Soft Matter 11, 1708-1722.

Wang, Y. en, Li, X. pei, Li, C. chuan, Yang, M. ming, Wei, Q. hua, 2015. Binder droplet impact mechanism on a hydroxyapatite microsphere surface in 3D printing of bone scaffolds. J. Mater. Sci. 50, 5014-5023.

Weickgenannt, C.M., Zhang, Y., Sinha-Ray, S., Roisman, I. V., Gambaryan-Roisman, T., Tropea, C., Yarin, A.L., 2011. Inverse-Leidenfrost phenomenon on nanofiber mats on hot surfaces. Phys. Rev. E - Stat. Nonlinear, Soft Matter Phys. 84. doi:10.1103/PhysRevE.84.036310 Wildeman, S., Visser, C.W., Sun, C., Lohse, D., 2016. On the spreading of impacting drops. J. Fluid Mech. 805, 636-655.

Worthington, A.M., 1908. A study of splashes. Longmans, Green, and Company.

Yarin, A.L., 2005. Drop Impact Dynamics: Splashing,Spreading,Receding,Bouncing... Annu. Rev. Fluid Mech. 38, $159-192$. doi:10.1146/annurev.fluid.38.050304.092144

Yonemoto, Y., Kunugi, T., 2017. Analytical consideration of liquid droplet impingement on solid surfaces. Sci. Rep. 7, 2362.

Young, T., 1805. An essay on the cohesion of fluids. Philos. Trans. R. Soc. London. 
Yu, Z., Wang, F., Fan, L.S., 2008. Experimental and numerical studies of water droplet impact on a porous surface in the film-boiling regime. Ind. Eng. Chem. Res. 47, 9174-9182.

Zygourakis, K., 1989. Transient operation of monolith catalytic converters: a two-dimensional reactor model and the effects of radially nonuniform flow distributions. Chem. Eng. Sci. 44, 2075-2086. 


\section{Highlights}

- The dynamics of droplet impact on a heated porous surface is studied experimentally.

- A new impact regime map together with regime transition criteria is proposed to determine droplet post-impingement behaviour.

- Significant differences are found between droplet impact on impermeable surfaces and porous surfaces.

- An analytical model with improved boundary layer description is developed to predict maximum spreading.

- The maximum-spread model predictions agree well with experiments. 